\title{
Caenorhabditis elegans Heterochromatin protein 1 (HPL-2) links developmental plasticity, longevity and lipid metabolism
}

\author{
Peter Meister ${ }^{1,2+}$, Sonia Schott ${ }^{3 \dagger}$, Cécile Bedet ${ }^{3}$, Yu Xiao $^{3}$, Sabine Rohner ${ }^{1}$, Selena Bodennec ${ }^{3}$, Bruno Hudry ${ }^{4}$,
} Laurent Molin ${ }^{5}$, Florence Solari ${ }^{5}$, Susan M Gasser ${ }^{1}$ and Francesca Palladino ${ }^{3^{*}}$

\begin{abstract}
Background: Heterochromatin protein 1 (HP1) family proteins have a well-characterized role in heterochromatin packaging and gene regulation. Their function in organismal development, however, is less well understood. Here we used genome-wide expression profiling to assess novel functions of the Caenorhabditis elegans HP1 homolog HPL-2 at specific developmental stages.

Results: We show that HPL-2 regulates the expression of germline genes, extracellular matrix components and genes involved in lipid metabolism. Comparison of our expression data with HPL-2 ChIP-on-chip profiles reveals that a significant number of genes up- and down-regulated in the absence of HPL-2 are bound by HPL-2. Germline genes are specifically up-regulated in hpl-2 mutants, consistent with the function of HPL-2 as a repressor of ectopic germ cell fate. In addition, microarray results and phenotypic analysis suggest that HPL-2 regulates the dauer developmental decision, a striking example of phenotypic plasticity in which environmental conditions determine developmental fate. HPL-2 acts in dauer at least partly through modulation of daf-2/IIS and TGF- $\beta$ signaling pathways, major determinants of the dauer program. $h p l-2$ mutants also show increased longevity and altered lipid metabolism, hallmarks of the long-lived, stress resistant dauers.
\end{abstract}

Conclusions: Our results suggest that the worm HP1 homologue HPL-2 may coordinately regulate dauer diapause, longevity and lipid metabolism, three processes dependent on developmental input and environmental conditions. Our findings are of general interest as a paradigm of how chromatin factors can both stabilize development by buffering environmental variation, and guide the organism through remodeling events that require plasticity of cell fate regulation.

\section{Background}

In most organisms, including mammals, environmental and physiological signals are integrated to regulate metabolism, development and life span. In eukaryotes, these processes are often associated with characteristic epigenetic changes brought about by the activity of chromatin-associated proteins and enzymes that influence the transition between chromatin states, thereby influencing transcriptional activity.

\footnotetext{
* Correspondence: francesca.palladino@ens-lyon.fr

+ Contributed equally

${ }^{3}$ Laboratory of Molecular and Cellular Biology, CNRS, Université de Lyon,

Ecole Normale Supérieure, 69364 Lyon Cedex 07, France

Full list of author information is available at the end of the article
}

Among the more universally conserved epigenetic factors are members of the Heterochromatin protein 1 (HP1) family. These contribute directly to the formation of nuclear heterochromatic domains, including telomeres and centromeres, through an interaction with trimethylated lysine 9 of histone H3 (H3K9me3) [1,2]. Both H3K9 methylation and HP1 binding at pericentromeric regions play a crucial role in chromosome segregation during mitosis $[3,4]$. Within euchromatic regions, however, the function of HP1 proteins in the control of gene expression is complex. This involves interactions with other proteins or RNA components, and leads to either gene activation or repression depending on the chromatin context [5-7].

\section{Biomed Central}

(c) 2011 Meister et al.; licensee BioMed Central Ltd. This is an open access article distributed under the terms of the Creative Commons Attribution License (http://creativecommons.org/licenses/by/2.0), which permits unrestricted use, distribution, and reproduction in any medium, provided the original work is properly cited. 
In many cases, the euchromatic functions of HP1 appear to be specific to different homologues within a species, which display dramatic differences with respect to subcellular localization and function. Drosophila HP1a acts as positive regulator of transcription by facilitating H3K36 demethylation through an interaction with the dKDM4A demethylase [8], while HP1c interacts with two related transcription factors, WOC and ROW, on active chromatin domains [9]. HP1a also functions in gene activation through association with nascent transcripts [10], while HP1c was found to link the histone chaperone complex FACT to active RNA polymerase II [11]. In mammals, the binding of HP1 $\gamma$ upstream of euchromatic genes is associated with silencing [12], while its association within the coding region of genes was found to affect transcriptional elongation [13]. More recently, $\mathrm{HP} 1 \gamma$ and $\mathrm{H} 3 \mathrm{~K} 9$ tri-methylation were also found to be associated with alternative splicing [14]. Although these studies suggest a role for HP1 family members at both heterochromatic and euchromatic sites, HP1's essential role in centromere function has confounded analysis of its role in development of most species. In Drosophila, for example, mutations in HP1a are associated with severe chromosome segregation defects due to a perturbation of centromeric heterochromatin [15]. The ensuing early larval lethality obscures other defects in gene regulation in the homozygous mutant, and renders a systematic analysis of HP1a function in fly development very difficult. Nonetheless, this early lethality could be bypassed by the conditional RNA interference (RNAi) inactivation of HP1 in transgenic flies. This resulted in a preferential lethality of males, due to the sex-specific regulation of genes encoding cell cycle regulators [16]. Intriguingly, cell type-specific effects have also been ascribed to the various HP1 homologues in mammals. Both in vivo localization and RNAi studies show that they play distinct roles in the differentiation of different cell types [17-20]. The specificity and sub-nuclear distribution of each homologue appears to be influenced by humoral signals and microenvironmental cues [21].

Exploiting the holocentric nature of Caenorhabditis elegans chromosomes, we are able to examine the role of HP1 during worm development without having to subvert an essential role in centromere stability. We have previously shown that deletion of the C. elegans hpl-2 gene, which encodes an HP1 homologue, results in temperature-sensitive non-lethal developmental abnormalities, including defects in vulval cell-fate specification, and desilencing of repetitive arrays in the germline [22,23]. Consistent with the holocentric nature of $C$. elegans chromosomes, no defects in chromosome segregation were observed in $h p l-2$ loss-of-function mutants $[22,24,25]$. However, in vulval cell-fate specification,
HPL-2 appeared to act through repression of specific genes, including $l i n-3 / E G F$ inducer and $l i n-39 / H O X$ [26]. In the present study, expression microarray analysis was performed using hpl-2 null mutants at embryonic and larval developmental stages. At the L3 larval stage, when the germline develops, germline-enriched genes are found to be overexpressed in hpl-2 mutant animals. This is consistent with a role for HPL-2 in preventing ectopic expression of germline genes in the soma $[27,28]$, and/or a repressive function in the germline [22]. Intriguingly, transcripts that are down-regulated in the absence of $h p l-2$ at the larval stage stem from genes involved in extracellular matrix-related functions and in lipid metabolism and transport. Comparison of our expression data with HPL-2 chromatin immunoprecipitation (ChIP)-on-chip profiles available through the modENCODE Consortium [29] shows that several of these genes are bound by HPL-2, suggesting a regulatory function.

This analysis has revealed a significant overlap between HPL-2-regulated genes and genes whose expression is altered in dauer diapause, an alternative developmental program that worms undergo under stressful conditions. We find that $h p l-2$ interacts genetically with both the transforming growth factor (TGF)- $\beta$ and the insulin/insulin-like growth factor-I-like receptor (IIR) signaling pathways, which are the major determinants of dauer formation [30]. Moreover, the dauer exit process can be restored by expressing HPL-2 in either neuronal or intestinal cells. Altogether, this suggests that HPL-2 regulates both the decision to enter and exit this developmental stage, as well as controlling the tissue remodeling that accompanies the dauer state.

We are able to attribute additional phenotypes related to dauer to HPL-2 function. Specifically, $h p l-2$ mutants show an increased lifespan that is dependent on both daf-2 and the downstream transcription factor daf-16/ FOXO, mimicking dauer-constitutive mutants of the daf-2/IIR pathway. At the same time, hpl-2 mutant animals show significant alterations in specific aspects of lipid metabolism, mediated at least in part through the regulation of key phospholipid metabolism enzymes. We suggest that these in turn influence lifespan through the regulation of lipid homeostasis. Together, our data suggest that rather than globally affecting the expression of a large number of genes, HPL-2 specifically controls genes whose expression impinges on the highly intertwined processes of dauer development, longevity and lipid metabolism.

\section{Results}

Overview of stage-specific transcriptional responses

Previous studies have suggested biological roles for HPL-2 at larval stages of C. elegans growth, while no 
obvious defects in embryonic development were observed in its absence [24]. To detect changes relevant for the $h p l-2$ phenotypes, we carried out DNA microarray experiments comparing expression profiles of wildtype and $h p l-2$ loss-of-function worms grown at $20^{\circ} \mathrm{C}$ and synchronized at the embryonic or L3 larval stages.

To analyze the microarray data, we applied a statistical threshold with a cutoff of $P<0.05$ (empirical Bayes statistics) and a fold change $>1.5$ for mutant versus wildtype samples. The curated list of genes showed a total of 1,794 embryonic transcripts and 1,160 L3 stage transcripts that were misregulated at least 1.5 -fold in the hpl-2 mutant background compared to wild-type animals (Additional file 1; NCBI [GSE33700]). To further validate the array findings, 12 genes with different developmental expression patterns and different biological functions were selected as targets for RT-PCR (Figure 1a). For all 12 genes, a good correlation between microarray data and quantitative PCR (qPCR) expression values was observed. Of the total number of responsive genes $(2,954)$, only $5.6 \%$ were found to be misregulated at both developmental stages (Figure 1b), confirming that HLP-2 has distinct biological roles at different stages of development. Although the vast majority of commonly regulated genes encode proteins of unknown function, a notable exception is lin-13, which was upregulated in both embryos and larvae. LIN-13 is a zinc finger protein required for HPL-2 recruitment to nuclear foci in embryos [23]. This indicates that a complex feedback control exists between HPL-2 and the important lineage factor LIN-13. Analysis of lin-13 expression in vivo using a green fluorescent protein (GFP) translational fusion revealed strongly increased GFP expression in hpl-2 mutant animals compared to wild type, further validating microarray results (Additional file 2).

In embryos, significantly more genes were down-regulated than up-regulated (1,344 and 450, respectively) in the absence of HPL-2, while approximately the same number of genes were found in each class in L3 larvae (615 and 545, respectively; Figure 1b). Although some of the down-regulated genes are likely to be indirect targets, these results suggest that HPL-2 may also play a significant role in gene activation, as reported for certain other HP1 family proteins in both Drosophila and mammalian cells $[5,11,13,31,32]$.

To analyze the responsive genes in more depth, they were divided into functional categories based on gene ontologies (GOs; Table 1). In embryos, up-regulated genes are slightly enriched in GO terms associated with

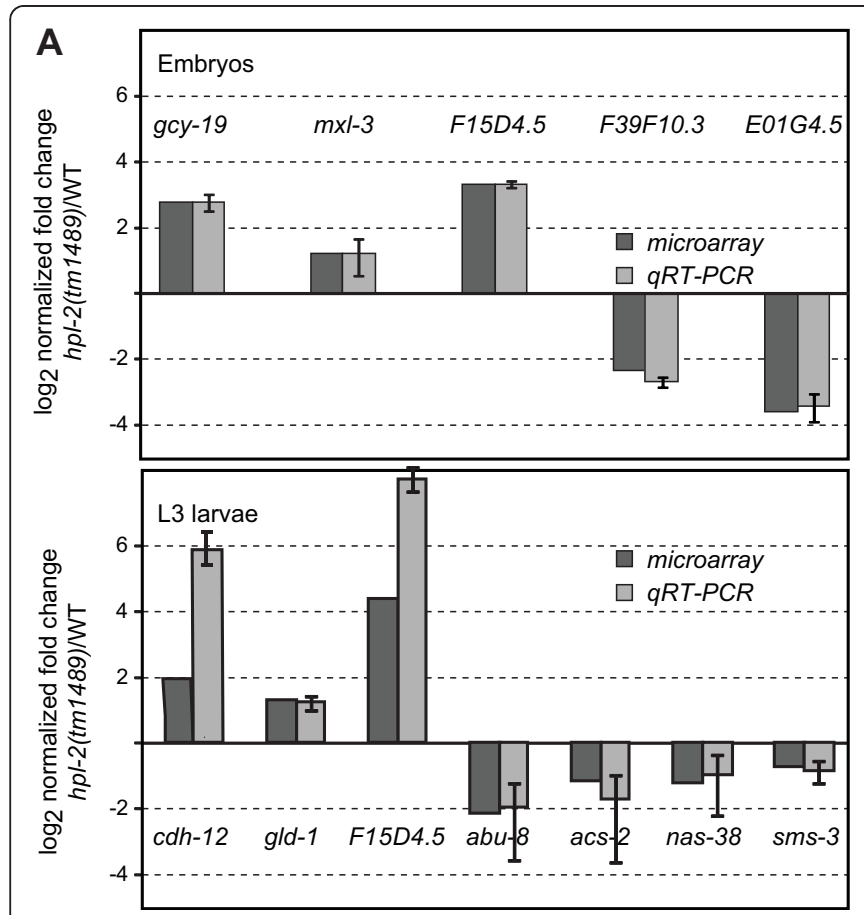

B

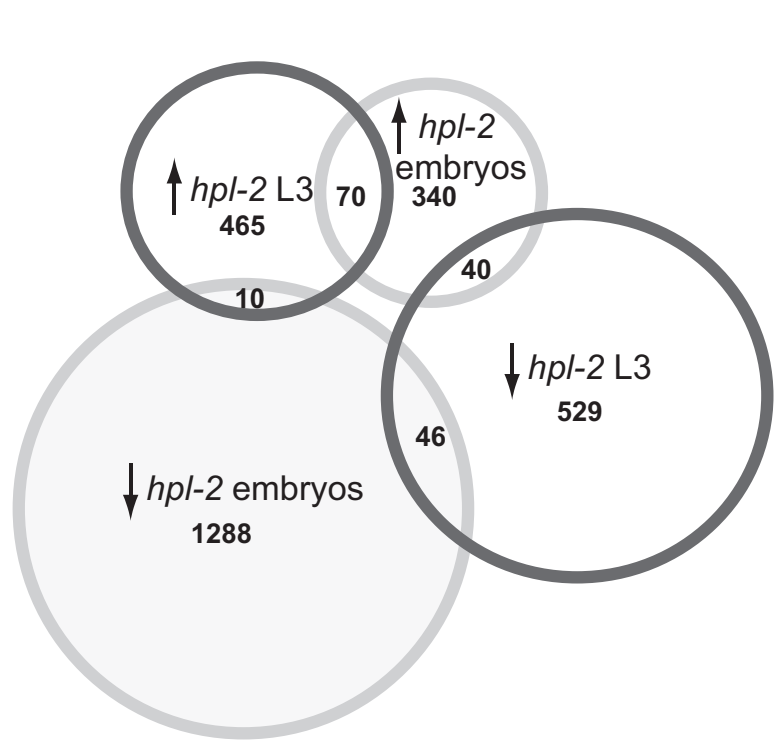

Figure 1 Validation of microarray results and overlap between embryonic and larval gene sets. (a) Correlation between results obtained by microarray and quantitative RT-PCR (qRT-PCR) for selected genes in embryos and L3 larvae. For qRT-PCR expression values, data are the mean of three independent biological replicas. Error bars indicate standard deviation. pmp-3 and $c d c-42$ were used for normalization and the RNA level of each gene of interest was normalized to the mean of both reference genes. (b) Venn diagram showing overlap between up- and down-regulated genes in embryonic and L3 larval stages. 
Table 1 Enrichment for Gene Ontology terms among hpl-2-regulated genes

\begin{tabular}{|c|c|c|c|}
\hline Term & Count & $P$-value & Fold enrichment \\
\hline \multicolumn{4}{|l|}{ Embryo down-regulated } \\
\hline GO:0006396 - RNA processing & 23 & 4.37E-05 & 2.7 \\
\hline GO:0006796 - phosphate metabolic process & 48 & 0.017 & 1.4 \\
\hline \multicolumn{4}{|l|}{ Embryo up-regulated } \\
\hline GO:0006631 - fatty acid metabolic process & 4 & 0.043 & 5 \\
\hline \multicolumn{4}{|l|}{ L3 down-regulated } \\
\hline GO:0009712 - catechol metabolic process & 5 & $3 \mathrm{E}-03$ & 8.0 \\
\hline GO:0043043 - peptide biosynthetic process & 4 & 0.02 & 8.0 \\
\hline GO:0046942 - carboxylic acid transport & 5 & $3 \mathrm{E}-03$ & 8.0 \\
\hline GO:0006631 - fatty acid metabolic process & 3 & 0.04 & 5.0 \\
\hline \multicolumn{4}{|l|}{ L3 up-regulated } \\
\hline GO:0007126 - meiosis & 15 & $3.21 \mathrm{E}-06$ & 4.7 \\
\hline GO:0022402 - cell cycle process & 19 & $3.12 \mathrm{E}-05$ & 3.1 \\
\hline GO:0045132 - meiotic chromosome segregation & 12 & $3.22 \mathrm{E}-05$ & 4.0 \\
\hline
\end{tabular}

Gene Ontology (GO) terms are from the biological process ontology. GO information was downloaded from DAVID [110]. In some cases, more specific subtypes of the listed parental terms were also significantly enriched.

lipid metabolic processes (Fisher exact test (FET) $P=$ 0.043 ), while down-regulated genes are enriched in GO terms associated with RNA metabolic processes (FET $P$ $=2 \times 10^{-6}$ ). L3 up-regulated genes are significantly enriched in GO terms associated with meiotic functions (FET $P=4 \times 10^{-6}$ ). The expression of many of these same genes is enriched in the germline (Additional file $3 a$ ) and is likely to reflect the role of HPL-2 and other chromatin-associated proteins in the repression of germ cell fate in the soma [28,33]. However, as our microarray analysis was performed on whole animals, some of these genes might also be up-regulated in the germline, where HPL-2 plays a role in germline transgene silencing and the related phenomenon of germline co-suppression [22,34].

The genes that are down-regulated in L3 larva by loss of HPL-2 activity are enriched in GO terms associated with alcohol metabolic processes (FET $P=0,003)$, transport (FET $P=0,003)$, and lipid metabolism (FET $P=$ $0,004)$. Intriguingly, visual inspection of the data revealed that four classes of genes (abu, nas, fipr, nspb) that are specifically down-regulated at this larval stage are tightly grouped together in mountain 29 of the $C$. elegans three-dimensional topographical expression map [35] (Additional file 3c). These genes may, therefore, be coordinately regulated by HPL- 2 . Because all of the phenotypes associated with $h p l-2$ loss of function concern post-embryonic development, we specifically focused our attention on genes showing altered expression at the L3 stage, as we considered these genes as those most likely to be directly responsible for stage-specific phenotypes.

Comparison of our expression data with HPL-2 ChIPon-chip profiles obtained in wild-type L3 larvae (available through the modENCODE Consortium [29]) revealed that a significant number of genes up- and down-regulated in the absence of HPL-2 are bound by HPL-2 (Additional file 4; up-regulated genes FET = 6.7 $\times 10^{-8}$; down-regulated genes FET $=1.2 \times 10^{-4}$ ). ChIPqPCR analysis confirmed HPL-2 enrichment on a subset of these genes (Figure 2). HPL-2 binding was found both within promoter and coding regions. No correlation was found between promoter or internal binding and either repression or activation of the bound gene in the absence of HPL-2. Therefore, HPL-2 may regulate gene expression by more than one mechanism and in a context-dependent manner, as observed for other HP1 family proteins $[7,14,36]$.

In most organisms HP1 binds methylated H3K9 [1,2]. This interaction appears to be conserved in C. elegans, as heterochromatin-like transgenic arrays enriched in methylated $\mathrm{H} 3 \mathrm{~K} 9$ require $\mathrm{HPL}-2$ for repression $[22,37,38]$. ChIP analysis confirmed that both H3K9me3 and HPL-2 are enriched on these arrays (Additional file $5)$. We therefore compared our expression data with ChIP-on-chip profiles of $\mathrm{H} 3 \mathrm{~K} 9 \mathrm{me} 1 / 2 / 3$ in wild-type L3 larvae, also available through the modENCODE Consortium [29]. We reasoned that this approach might help identify genes whose expression is directly regulated by the binding of HPL-2 to methylated H3K9. For each gene list, we calculated the median $\mathrm{H} 3 \mathrm{~K} 9 \mathrm{me} 1 / 2 / 3$ signal over the gene body or the promoter and compared this value to the values obtained for expression-level matched genes. We then plotted the distribution of these median signals as box-whisker representation. In this representation, the bar indicates the median for distribution over genes and the upper and lower edges of the box represent the 25 th and 75 th percentile, respectively. For the genes that require HPL-2 for full repression, we observe a significantly higher signal for H3K9 

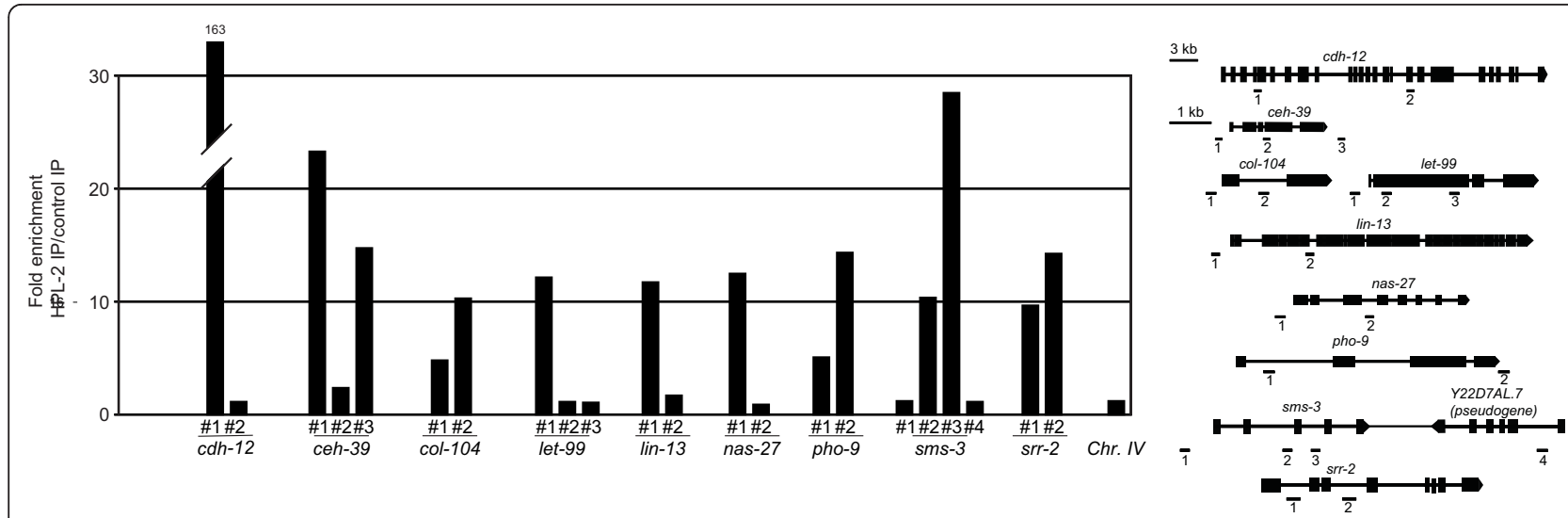

Figure 2 HPL-2 binding to target genes. Worm extracts from synchronized L3 worms were subjected to immunoprecipitation (IP) using either HPL-2-specific antibodies or pre-immune serum as control. For each gene tested, a cartoon shows the position of the primers used for quantitative PCR (qPCR) analysis and a histogram representing the fold-enrichment, calculated as the ratio between signal from the antibodies and signal from pre-immune serum, from chromatin immunoprecipitation (ChIP) experiments along the gene. chIV is a primer from an intergenic region on chromosome IV used as an internal control. Similar results were obtained for two to three independent experiments.

mono- and di-methylation, and to a lesser extent trimethylation, compared to expression-matched promoters and gene bodies from wild-type cells (Additional file 6; Wilcoxon test $P=10^{-89}, 10^{-83}, 10^{-34}$, respectively, for promoters, $10^{-44}, 10^{-39}$ and $10^{-18}$, respectively, for gene bodies). This suggests that at least part of the derepression in $\mathrm{hpl}-2$ mutant larvae is indeed direct, that is, due to HPL-2 binding to methylated H3K9. For genes that show lower expression levels in the hpl-2 mutant, the correlation with methylated H3K9 was much weaker, suggesting indirect effects on gene expression, or possibly the existence of alternative mechanisms for recruiting HPL-2 to euchromatic sites. One such mechanism may be through the LIN-13 zinc finger protein [23].

\section{$h p l-2$ regulates a subset of dauer genes}

Visual inspection revealed that both up- and downregulated transcripts in $h p l-2$ mutant animals show a significant overlap with genes regulated in animals undergoing dauer arrest [39] (Figure 3a, b; FET $P<2$ $\times 10^{-6}$ ). In a favorable environment, C. elegans develops into an adult through four larval stages (L1 to L4), but in response to starvation or overcrowding, larvae arrest development at the second molt (L2) to form dauer larvae. Dauer animals are non-feeding and stress-resistant, and can remain in this state for months until environmental conditions become favorable again. Dauer formation has been widely used as a model to study the regulatory mechanisms governing morphological change during organismal development [40]. The list of genes whose expression changes during dauer arrest was obtained by comparing expression profiles of wild-type larvae at the L2/L3 larval stage transition to animals undergoing dauer larva formation (pre-dauer L2d/dauer). Our data were obtained from a very similar developmental stage (early L3), which makes the observed overlap particularly relevant. Significantly, we also observed overlap between genes upregulated during dauer exit [41] and genes down-regulated in the absence of $h p l-2$ (FET $P=2 \times 10^{-16}$; Additional file $3 \mathrm{~b}$ ).

The commonly regulated genes fall into four classes. The first class includes genes encoding collagens and metalloproteases involved in the synthesis and degradation of the extracellular matrix and cuticle physiology $[39,42,43]$. The second group consists of members of the Hedgehog (Hh)-related-family, which are downregulated in both data sets. The nematode Hh-related genes encode secreted proteins mostly expressed in the epidermis, which secretes the lipid- and collagen-rich cuticle, and in neurons and neuronal support cells required for the response to the environment [44-46]. Consistent with a possible role of these proteins in cuticle formation, inactivation of some $\mathrm{Hh}$-related genes causes cuticle abnormalities and molting defects $[45,46]$. The co-regulation of $\mathrm{Hh}$-related genes and structural components of the cuticle suggest that these genes could regulate the production of the dramatically different cuticles of dauer and reproductive L3 [47] through coordinated regulation by HPL-2. The third class of dauer and $h p l$-2-sensitive genes comprises a number of transporters whose expression is reduced upon dauer entry. These include members of the ABC transporter superfamily ( $p g p-5,7$ and 12), and members of the MSF1 Major facilitator superfamily (F09A5.1, F14D7.6 and F53H8.3). Finally, the fourth and last class consists of cytochromes, enzymes 


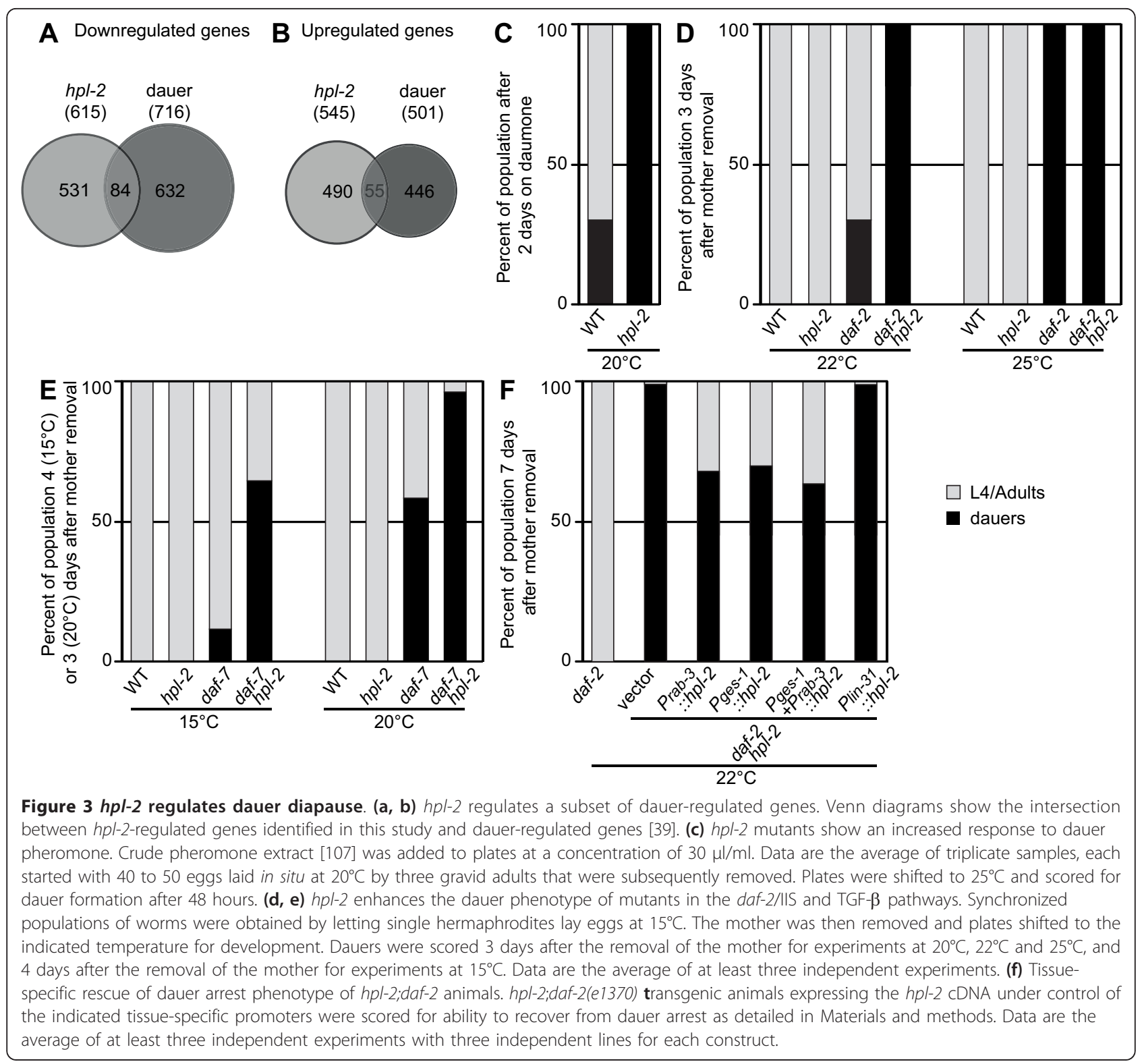

involved in protection from toxins, hormone biosynthesis and other functions. Of the 81 members of the P450 family in C. elegans, 8 are present in the $h p l-2$ microarray. Three of these (cyp-33C9, cyp-14A5, and cyp-37B1) are down-regulated in hpl-2 mutants and in dauer, while two (cyp-25A2 and cyp13A5) are up-regulated in hpl-2 mutants and upon dauer entry $[39,48]$. Genes from each of these classes are also induced upon dauer exit [41], suggesting an important function in the regulation of both dauer entry and exit programs. HPL-2 binding and H3K9 methylation could be detected on a number of these dauer-regulated genes, including $c d h-10, c d h-12$, Y55F3AM.14, and srr-2 [49] (Figure 2), suggesting that they are likely to be direct targets of HPL- 2 .

\section{HPL-2 influences dauer entry and exit}

The above results prompted us to test whether $h p l-2$ mutants are associated with dauer phenotypes. High temperature $\left(27^{\circ} \mathrm{C}\right)$, scarce food and a secreted dauer pheromone influence dauer formation. While higher temperatures alone failed to induce a dauer phenotype in $h p l-2$ animals, when plates with identical bacterial lawns were seeded with the same number of worms at $25^{\circ} \mathrm{C}$, we observed that starved plates containing $h p l-2$ mutant worms reproducibly had many more dauers than wild-type plates (data not shown). While this is not a quantitative assay, the observation nonetheless suggested that $h p l$-2-deficient animals enter dauer more easily under starved and crowded conditions at $25^{\circ} \mathrm{C}$. We therefore tested whether $h p l-2$ mutants are more 
sensitive to dauer pheromone, an indicator of population density produced by the worms, which induces dauer formation at high concentrations.

At pheromone concentrations that trigger dauer formation in $23 \%$ of wild-type animals after 48 hours at $25^{\circ}$ C, $97 \%$ of hpl-2 mutant animals entered dauer (Figure 3c). Therefore, $h p l-2$ mutants are associated with a hypersensitivity to dauer pheromone, which becomes evident under strong dauer-inducing conditions. When shifted to $20^{\circ} \mathrm{C}$ following exposure to dauer pheromone, a large majority of wild-type worms exit the dauer stage after 2 to 3 days. In contrast, only 15 to $20 \%$ of $h p l-2$ mutant worms exit dauer under the same conditions. We conclude that $h p l-2$ mutants exhibit both dauer entry and exit defects, namely hypersensitivity for dauer entry and a failure to exit efficiently.

The second C. elegans HP1 homologue, hpl-1, acts redundantly with $h p l-2$ in postembryonic development [24]. However, hpl-1 does not appear to act either alone or redundantly with $h p l-2$ in dauer development, since dauer formation was not impaired in either hpl-1 (tm1624) single or hpl-1(tm1624); hpl-2(tm1489) double mutants at any of the temperatures tested.

\section{HPL-2 synergizes with the DAF-2/IIS pathway for dauer entry and exit}

We next tested whether $h p l-2$ interacts genetically with either of the well-characterized dauer pathways: DAF-2/ insulin-like signaling (IIS) and DAF-7/TGF- $\beta$. Mutations in either of these pathways have been isolated as dauer constitutive (daf-c), forming dauers even under nondauer-inducing conditions [50]. We first constructed double mutants with the daf-2(e1370) allele, a wellestablished sensitized background for assaying a weak dauer phenotype [51]. While daf-2 single mutants do not form dauer at $20^{\circ} \mathrm{C}, 10$ to $20 \%$ of double hpl-2;daf-2 mutants entered dauer at this temperature (Figure 3d, $20^{\circ} \mathrm{C}$ ). This difference between single and double mutants was not detected at $22^{\circ} \mathrm{C}$, a temperature at which single daf-2(e1370) mutants all enter dauer for approximately 3 days, then recover and resume development to become reproductive adults (data not shown). However, 3 days after egg-laying, when only $30 \%$ of the daf-2 single mutants remained as dauers, $98 \%$ of $h p l-2$; daf-2 double mutants were still in the dauer stage (Figure $3 \mathrm{~d}, 22^{\circ} \mathrm{C}$ ). Under these conditions, the block persisted for more than two weeks. At a slightly higher temperature, $25^{\circ} \mathrm{C}, 100 \%$ of the population remained in the dauer stage in both genetic backgrounds after 3 days (Figure $3 \mathrm{~d}, 25^{\circ} \mathrm{C}$ ). We conclude, therefore, that $h p l-2$ significantly enhances the dauer phenotype of $d a f-2$ mutants.

Like daf-2(e1370) mutants, daf-7(e1372) mutants show a temperature-sensitive dauer constitutive phenotype
[52]. At the semi-permissive temperatures of $15^{\circ} \mathrm{C}$ and $20^{\circ} \mathrm{C}$, hpl-2;daf-7 double mutant animals show a greatly enhanced dauer arrest phenotype compared to single daf-7 mutants (Figure 3e). Our results thus suggest that HPL-2 acts in parallel or downstream to the IIS and TGF- $\beta$ pathways to influence dauer through the regulation of genes important for both dauer entry and dauer exit processes. Given that this is a stress-induced differentiation event, our results implicate HPL-2 in communication between environment and a chromatincontrolled genetic response to stress.

\section{HPL-2 acts in the nervous system and intestine to influence dauer development}

The decision to enter dauer is triggered by chemosensory stimuli. Two major head sensory organs, called amphids, are critical to dauer formation and both DAF28 /insulin and DAF-7/TGF- $\beta$ are expressed in a subset of sensory neurons to impact dauer development [53-55]. These hormones in turn regulate the activity of widely expressed downstream receptors and transcription factors, which regulate dauer remodeling in other tissues. To establish in which tissue HPL-2 acts to influence dauer development, we carried out tissue-specific rescue experiments on $h p l-2 ; d a f-2(e 1370)$ animals raised at $22^{\circ} \mathrm{C}$ (Figure $3 \mathrm{f}$ ). While at this temperature all $d a f-2$ animals reenter the reproductive cycle after 7 days, less than $1 \%$ of the double $h p l-2 ; d a f-2$ mutants ever exit the dauer stage. Expression of $h p l-2$ under the control of either the pan neuronal $r a b-3$ promoter or the intestinal ges -1 promoter allowed more than $30 \%$ of $h p l-2 ; d a f-2$ (e1370) mutant animals to exit the dauer stage. By contrast, expression of $h p l-2$ under the control of the lin-31 promoter, which is expressed in vulval precursor cells, failed to promote rescue. Furthermore, we confirmed that GFP expression of the rab-3p::GFP::hpl-2 rescuing transgene was limited to neuronal cells in $h p l-2 ; d a f-2$ mutants (Additional file 7 ). These results suggest that the rescue observed with the $r a b-3$ and ges- 1 promoters is unlikely to be due to ectopic expression in additional cell types, but reflects the tissue-specific expression of these transgenes. The fact that rescue is partial could stem from insufficient induction of these promoters during dauer and/or from additional expression requirements in other tissues. Neuronal and intestinal expression together did not result in better rescue, however, suggesting that in these tissues HPL-2 does not have additive functions, but acts in the same process.

\section{hpl-2 modulates lifespan through the IIS pathway}

Our results suggest that $h p l-2$ synergizes with the IIS pathway to control dauer development. Given that the IIS pathway is also a well-established regulator of lifespan in C. elegans, Drosophila and mice [56], we 
performed lifespan analysis of $h p l-2$ null mutants at the permissive temperature $\left(20^{\circ} \mathrm{C}\right)$. We observed a reproducible increase in the mean lifespan of $h p l-2$ animals by $17 \%$ on average (average lifespan: hpl-2(tm1489), $15.1 \pm$ 0.31 days $(n=287)$; wild-type, $12.9 \pm 0.25$ days; log rank test $P<10^{-3}$; Figure $4 \mathrm{a}$ ). To confirm that the increased lifespan is due to inactivation of $h p l-2$ and not to a background mutation, we repeated lifespan assays of animals in which $h p l-2$ was inactivated by RNAi feeding. $h p l-2(R N A i)$ only partially inactivates $h p l-2$ activity and compared to $h p l-2$ loss of function results in weaker phenotypes only apparent at higher temperatures $[22,23]$. However, similarly to the hpl-2 mutant, longevity of $h p l-2(R N A i)$ animals raised at $20^{\circ} \mathrm{C}$ and shifted to $25^{\circ} \mathrm{C}$ at the $\mathrm{L} 4$ stage was extended by $18 \%$ on average compared to control animals (Additional file 8), confirming that HPL-2 is required for normal longevity. Lifespan extension in the absence of HPL-2 is unlikely to be related to a germline proliferation defect, as $h p l-2$ mutants have a wild-type brood size and germline cell number at $20^{\circ} \mathrm{C}$ [22,23] (Additional file 9).

To assess whether the lifespan increase observed in hpl-2 mutants depends on the IIS pathway, we analyzed the lifespan of $h p l-2 ; d a f-2$ double mutants. The two-fold increase in lifespan of daf-2(e1370) mutants was unchanged in hpl-2;daf-2 animals (average lifespan: daf2(e1370), $26.2 \pm 0.85$ days $(n=95)$; daf-2(e1370); hpl-2 (tm1489), $24.8 \pm 0.97$ days $(n=84) ; \log \operatorname{rank}$ test $P=$ 0.271 ; Figure $4 \mathrm{~b})$. Therefore, the $h p l-2$ lifespan phenotype may rely on IIS signaling. The transcription factor DAF-16/FOXO acts downstream of $d a f-2 /$ IIR and is essential for lifespan extension by daf-2. We therefore tested whether the $h p l-2$ mutant lifespan phenotype also requires DAF-16/FOXO. hpl-2(tm1489);daf-16(mu86) mutants had a lifespan indistinguishable from that of daf-16(mu86) alone, which is $16 \%$ shorter than wildtype worms (average lifespan: daf-16(mu86), $11.9 \pm 0.44$ days $(n=112)$; daf-16(mu86); hpl-2(tm1489), $11.03 \pm$ 0.27 days $(n=109)$; $\log$ rank test $P=0.05$; Figure $4 \mathrm{c})$. Furthermore, the $h p l-2$ effect on longevity is not due to altered expression of genes encoding proteins involved in the IIS pathway, as the levels of $d a f-16$ and other major components of the pathway, including daf-2, age$1, a k t-1, a k t-2$ and $d a f-18$, were not altered in $h p l-2$ mutants (Additional file 1). Taken together, our results suggest that $h p l-2$ requires the activity of daf-16 to modulate longevity in C. elegans and that $h p l-2$ may be a novel co-regulator of daf-16-controlled genes.

To better define this relationship, we looked for overlap with the 514 genes that microarray analysis by Murphy et al. [57] found to be modulated by DAF-16; 46 of the genes that we found to be misregulated in the absence of $h p l-2$ activity overlap with genes regulated by DAF-16. Of these, 16 are genes repressed in $h p l-2$ and in long-lived $d a f-2$ pathway mutants, and activated in daf-2;daf-16 mutants, reflecting DAF-16 dependence (Additional file 2e; $P=0.003$ ). We also compared our dataset to a recent transcriptional profile to identify genes whose expression changes over the C. elegans lifespan [58]. Out of 1,217 ageing-associated genes, 66 were down-regulated in the absence of $h p l-2$, representing a significant enrichment (Figure S2f; $P=5 \times 10^{-7}$ ). Taken together, these analyses suggest that the effect of $h p l-2$ on longevity may be mediated, at least in part, through the regulation of longevity-associated genes, some of which may be DAF-16-dependent.

\section{hpl-2 mutants do not show altered daf-16 localization or increased stress resistance}

Similar to mammalian FOXO transcription factors, translocation of DAF-16 from the cytoplasm to the nucleus is required for activation, and has been observed in animals with reduced DAF-2/IIS signaling and in response to stresses such as heat shock or starvation [59]. Using a previously described DAF-16::GFP reporter [60], we observed no change in DAF-16 localization in animals lacking HPL-2 (data not shown and Additional file 10). Therefore, HPL-2 does not appear to impinge on longevity by altering DAF-16 localization.

Many long-lived mutants also exhibit increased resistance to environmental stress. However, hpl-2 mutants are not significantly more resistant to oxidative stress, as measured on paraquat (Additional file 11), and are intrinsically thermosensitive. Therefore, the increased longevity of $h p l-2$ mutants appears to be uncoupled from increased resistance to environmental stressors, as already observed in other contexts [55,61-64]. Consistently, we did not observe increased expression of genes commonly associated with increased stress resistance for example, the $m t l-1$ metallothionein gene and the mitochondrial sod-3 superoxide dismutase gene - while expression of the heat shock proteins $h s p-16$ and $h s p-12$ actually decreased [65-67] (Additional file 1).

\section{hpl-2 regulates fat metabolism}

Adipose tissue has been implicated in the regulation of longevity in a number of species [68-70]. In C. elegans, lipid hydrolysis in fat storage tissue was recently shown to prolong life span, connecting the metabolic functions of adipose tissue to lifespan control [71]. Genes associated with fatty acid metabolism are over-represented in the set of hpl-2 down-regulated genes (Table 1), prompting us to test whether $h p l-2$ mutants may have defects in lipid metabolism that could contribute to the longevity phenotype. Down-regulated genes include the fat-7 $\Delta 9$ fatty acid desaturase, acs-2, an acyl-CoA synthetase, and ech-1, an enoyl-CoA hydratase. hpl-2 mutants raised at the non-permissive temperature are 

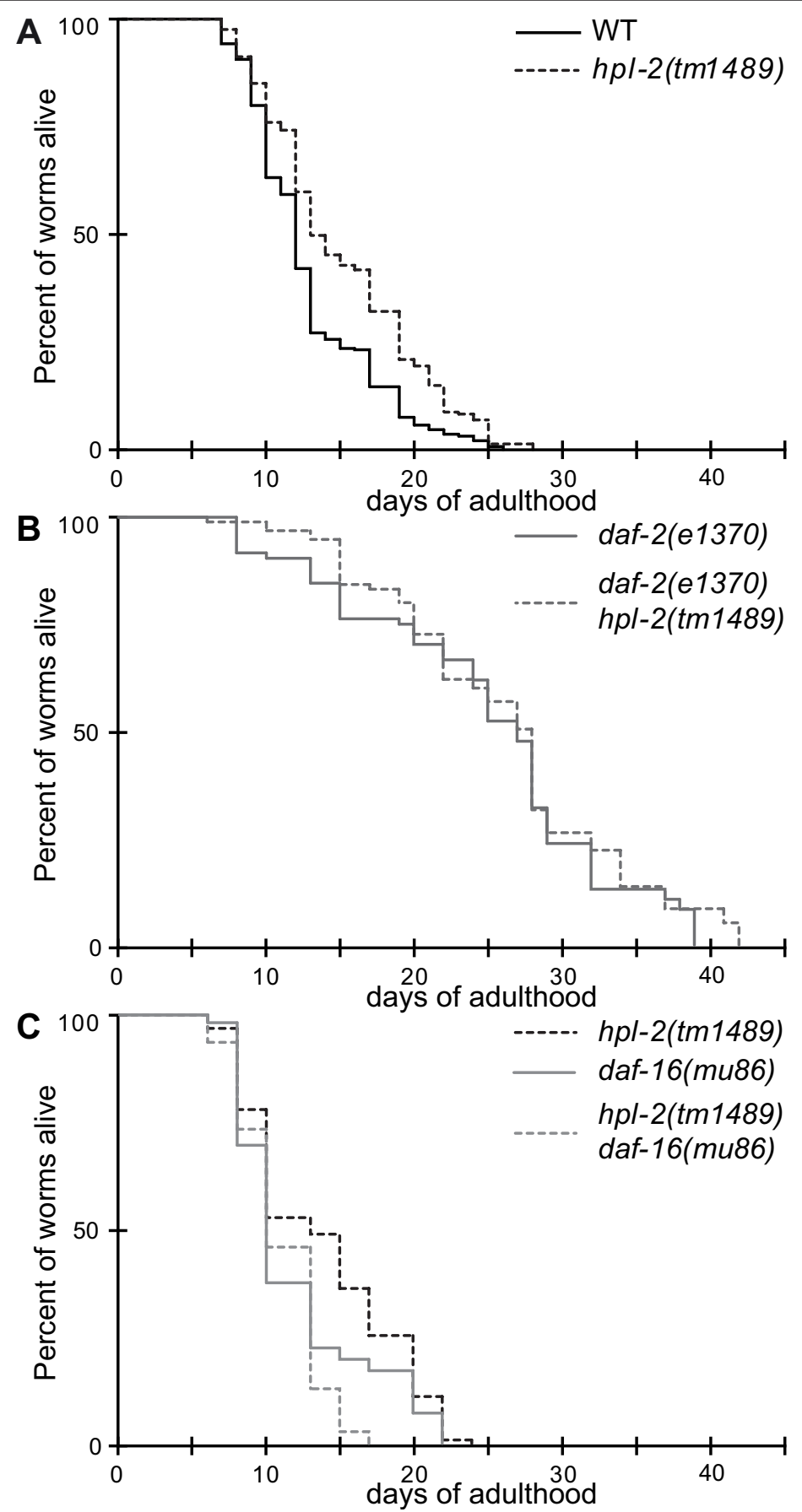

Figure 4 HPL-2 modulates lifespan by acting through the daf-2/IIS pathway. (a) Survival curve of wild-type and hpl-2(tm 1489) animals. hpl2(tm1489) mutation increases average lifespan by 17\% (average lifespan: $h p l-2$ (tm1489), $15.1 \pm 0.31$ days $(n=287)$; wild type (WT), $12.9 \pm 0.25$ days $(n=280)$; log rank test $\left.P<10^{-3}\right)$. (b) Survival curve of daf-2(e1370); hpl-2(tm1489) double mutants compared to daf-2(e1370) single mutants. hpl-2(tm 1489) did not further increase daf-2(e1370) mutant lifespan (average lifespan daf-2(e1370), $26.2 \pm 0.85$ days $(n=95)$; daf-2(e1370); $h p l-2$ (tm1489), $24.8 \pm 0.97$ days ( $n=84$ ); log rank test $P=0.271$.). (c) Survival curve of daf-16(mu86); $h p l-2(\mathrm{tm} 1489)$ compared to daf-16(mu86). daf-16 (mu86) mutation suppressed hpl-2(tm1489) mutant lifespan phenotype (average lifespan: daf-16(mu86), $11.9 \pm 0.44$ days ( $n=112$ ); daf-16(mu86); hpl-2(tm1489), $11.03 \pm 0.27$ days $(n=109) ; \log$ rank test $P=0.05)$. 
transparent, resembling starved animals (data not shown). This 'clear' phenotype has been associated with decreased fat storage in the intestinal compartment [72]. However, using the neutral lipid dye Oil red $\mathrm{O}$ [73], no reproducible difference in staining intensity was observed between wild-type and $h p l-2$ mutant animals at either permissive or non-permissive temperatures (Figure 5a, b and data not shown), ruling out any gross alteration in lipid content.

Quantitative lipid analysis following solid phase extraction [74] revealed more subtle, highly reproducible differences in lipid composition in hpl-2 mutant animals
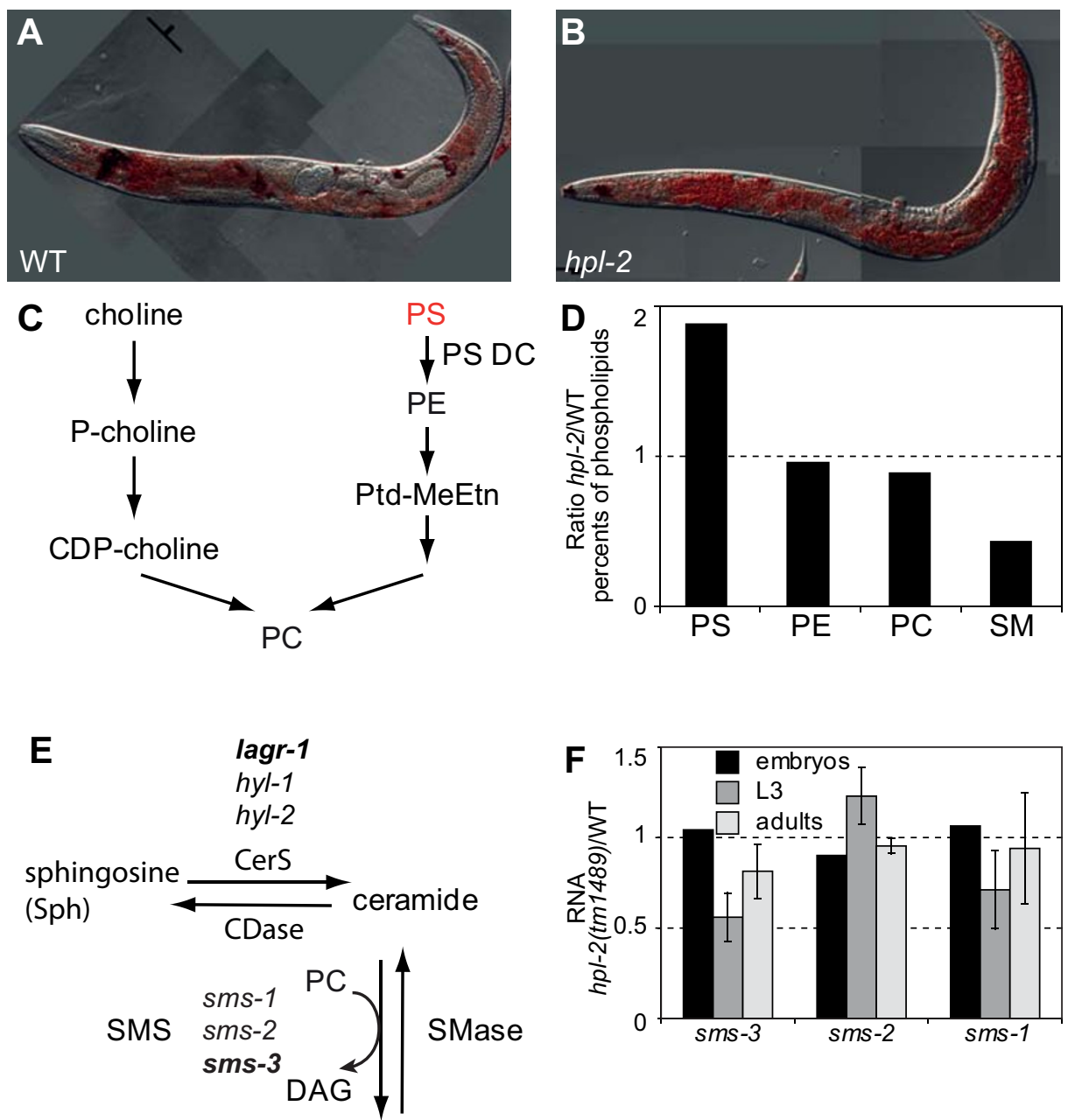

sphingomyelin

(SM)

Figure 5 HPL-2 is a regulator of phospholipid metabolism. (a, b) Oil Red O representative images of wild type (WT) (a) and hpl-2(tm1489) (b) animals. Worms are F1 progeny of $\mathrm{L} 4$ hermaphrodites shifted to $25^{\circ} \mathrm{C}$. Images were taken with a CoolSnap Color Camera with 700 ms exposure time. Scale bar $=50$ mm. (c) Simplified overview of phosphatidyl choline (PC) metabolism in C. elegans. P-choline, phosphorylcholine; CDP-choline, cytidyldiphosphate choline; PC, phosphatidylcholine; PS, phosphatidylserine; PS DC, phosphatidylserine decarboxylase; PE, phosphatidylethanolamine; Ptd-MeEtn, phosphatidylmonomethylethylamine. Intermediates whose levels are altered in hpl-2 mutant worms compared to wild type are shown in red. (d) Phospholipid content analysis in wild-type and hpl-2 mutant worms. Bars represent the amount of each lipid species found as a percentage of the total phospholipid content. PS, phosphatidylserine; PE, phosphatidylethanolamine; PC, phosphatidylcholine; SM, phingomyelin. Data are the average of two independent cultures. (e) Metabolism of sphingomyelin and ceramide. De novo sphingomyelin synthesis is mediated by sphingomyelin synthase (SMS), which transfers the phosphorylcholine moiety from phosphatidylcholine (PC) onto ceramide, forming sphingomyelin and diacylglycerol (DAG). In C. elegans there are three SMS genes, sms-1, -2, and -3. Ceramide can be generated either by the action of sphingomyelinase (SMase) or by de novo synthesis through the enzyme ceramide synthase (CerS, lagr-1, hyl-1 and hyl-2 in C. elegans). (f) hpl-2 regulates sms-3 mRNA levels. hpl-2/N2 ratios for sphingomyelin synthase sms genes at different developmental stages. Experiments were performed on three independent synchronized L3 cultures and on two adult and embryonic cultures. Reference genes are pmp-3 and $c d c-42$. Normalization was performed using the mean of both reference genes. Data are the mean of independent biological replicas. 
at the permissive temperature. Consistent with the Oil red $\mathrm{O}$ staining results, no difference in the total content and composition of neutral lipids was observed and levels of triacylglycerides and fatty acids were unchanged in hpl-2 animals compared to wild type (Additional file 12 and data not shown). In contrast, phospholipid analysis showed significant changes in phospholipid content (Figure 5d). Higher amounts of phosphatidylserine (PS) were observed in hpl-2 mutant animals, whereas no increase in phosphatidylethanolamine $(\mathrm{PE})$, the decarboxylation product of PS, was observed. These results may therefore reflect changed expression or function of PS decarboxylase leading to lower synthesis of PE. Phosphatidylcholine (PC) is the predominant membrane lipid in eukaryotes and also functions in signal transduction pathways. Although amounts of PC were slightly reduced in $h p l-2$ mutant worms, the fact that we do not observe any obvious defects in hpl-2 mutants at the permissive temperature suggests either that the observed decrease in PC is not large enough to impinge on PC mediated processes, or that compensatory mechanisms exist.

Of the different classes of phospholipids analyzed, the most dramatic change was observed for sphingomyelin (SM), whose content was reduced by more than $60 \%$ in hpl-2 mutants. SM is a vital component of cellular membranes and plays an important role in signal transduction and membrane trafficking [75]. Synthesis of SM involves a transfer of phosphorylcholine from PC to ceramide by sphingomyelin-synthases (SMSs; Figure 5E). Expression of lagr-1, encoding a ceramide synthase (CerS), is decreased in hpl-2 mutant animals. This could potentially result in lower levels of ceramide, thereby influencing SM levels. However, the total content of ceramides (hydroxylated and nonhydroxylated) was not affected in the hpl-2 mutant context (Additional file 12). Therefore, the decrease in SM levels is more likely to be due to the down-regulation of de novo SM synthesis rather than enhanced degradation. C. elegans contains three SMS homologues, one of which $(s m s-3)$ is downregulated in hpl-2 mutants. qRT-PCR analysis confirmed that sms-3 RNA levels are decreased approximately twofold with respect to wild type in L3 animals, with a smaller effect in young adults (Figure $5 \mathrm{f}$ ). Similarly, sms1 levels also appeared to be slightly reduced in L3, but no significant change in sms-2 RNA levels was observed, nor were changes in $s m s-3$ or $s m s-1$ levels observed at the embryonic stage. As shown in Figure 2, ChIP experiments revealed a small but reproducible enrichment of HPL-2 binding within the sms-3 coding regions in L3 larvae. Therefore, it is likely that HPL-2 directly influences SM levels through the regulation of sms-3 transcription.

\section{Discussion}

Because C. elegans chromosomes are holocentric and lack centromeric heterochromatin, HP1 proteins are dispensable for chromosome segregation and mitotic viability in this organism $[23,25]$. We have exploited this fact to examine in detail the role of one of the C. elegans HP1 homologues, HPL-2, in regulating developmental pathways of gene expression, a second physiological function ascribed to heterochromatin. By comparing the effects of $h p l-2$ deletion at different stages of development, we have shed light on a novel role for this HP1 family member in dauer diapause, longevity and lipid metabolism. These three processes have in common an extremely tight response to environmental factors. Thus, our data link a response to environmental factors to the epigenetic regulator HPL-2. At least some of the genes identified in this study are shown by CHIP-on chip to be bound by HPL-2, and are therefore likely to represent direct targets.

We show that hpl-2 plays a role in the choice between dauer and non-dauer development, a striking example of phenotypic plasticity in which environmental conditions determine developmental fate. Many of the genes downregulated in hpl-2 mutant larvae at the L3 stage show high expression in wild-type L3 and dramatic reduction in dauer. These include the cadherins $c d h-10$ and $c d h-12$, the metalloprotease nas-27 and the collagen col-104 [49]. Conversely, genes up-regulated in $h p l-2$ mutants often show low expression in wild-type L3 and strong expression in dauer. Down-regulation of metalloproteases, collagen genes, and Hh-related peptides in $h p l-2$ mutants most likely reflects synthesis and remodeling of the cuticle, an important feature of the dauer program. Their down-regulation in hpl-2 mutants may facilitate entry into dauer and impair dauer exit, which are the two phenotypes we observe in animals lacking HPL-2.

Recently, post-dauer animals have been shown to have markedly altered genome-wide histone tail modifications, as well as modified gene expression profiles [76]. Furthermore, mutations of genes implicated in chromatin function, including $h p l-2$, were found to abolish or alter changes in gene expression between control and post-dauer animals. Remodeling of chromatin architecture may therefore play an essential role in the establishment or maintenance of the post-dauer expression changes. The inability of $h p l-2$ worms to exit dauer suggests that $h p l-2$ also functions during the dauer stage to activate the transcriptional program required to exit this developmental stage and re-enter the reproductive life cycle. Consistently, we also found a significant overlap between genes down-regulated in the absence of HPL-2 and genes whose expression increases upon dauer exit. 
HPL-2 functions in dauer through the DAF-2/IIS and the TGF- $\beta$ pathways. The decision to enter or exit dauer is mediated by these neuroendocrine signals acting through sensory neurons $[40,77]$. These in turn regulate the developmental and metabolic shifts in remodeled tissues. Although HPL-2 is ubiquitously expressed, we show using cell type-specific rescue that HPL-2 is sufficient in either the nervous or the intestinal system to induce partial rescue of the dauer exit phenotype. In the nervous system, it may function to regulate the activity of widely expressed downstream receptors and transcription factors, while in intestinal cells it may more directly mediate the dramatic reshaping of this tissue, a process that can be separated from the remodeling of other tissues [78]. Supporting a cell autonomous function for HPL-2 in neuronal cells, we find that neuronally expressed genes are significantly overrepresented in the $h p l-2$ microarray set (Additional file 3; FET $P<$ $10^{-9}$ for up-regulated genes, $P<3.10^{-3}$ for down-regulated genes). In both tissues, HPL-2 appears to be important for environmentally induced changes in tissue-modifying gene expression.

We also show that mutation of $h p l-2$ leads to a $17 \%$ increase in longevity. RNAi-based screens have identified a number of additional chromatin regulators as being important components of longevity, including the set-9 and set-15 putative H3K9 methyltransferases [79]. More recently, members of an $\mathrm{H} 3 \mathrm{~K} 4$ histone methylation complex were also found to regulate lifespan [80], suggesting that epigenetic mechanisms are likely to play an important role in the ageing process. In Drosophila, changes in HP1 copy number were not found to have any effect on longevity [81]. However, whole genome profiling has shown a dramatic redistribution of HP1 and H3K9 methylation in aging flies [82]. Similarly, aging human cells show decreased H3K9me3 and HP1 $\gamma$ staining [83]. Although the specific functional consequences of these age-related changes have not been directly determined, changes in gene expression are likely to be involved.

Here we demonstrate that lifespan extension by mutation of $h p l-2$ depends on both DAF-2 and DAF-16/ FOXO. DAF-16 is a key regulator of longevity, metabolism and dauer diapause, and several microarray experiments have been carried out to identify potential DAF16 targets. The requirement for $d a f-16$ activity for the hpl-2 longevity phenotype could reflect regulation of some of the same target genes. Although all of the published daf-16 microarray studies have been carried out on adult animals $[57,84,85]$, while our analysis was carried out on early L3 larva, we were nonetheless able to observe a limited overlap between potential DAF-16 targets identified by Murphy et al. [57] and hpl-2 regulated genes. Some of these same genes are also regulated upon dauer entry, suggesting that HPL-2 may act in dauer and ageing at least in part through a common mechanism that is dependent on DAF-16.

The longevity of $h p l-2$ mutants may also be related to the function of HPL-2 in repressing germ-cell fate in the soma. A significant number of genes up-regulated in L3 larvae in the absence of $h p l-2$ are germline-expressed genes, and like long-lived daf-2/IIS mutants [27], hpl-2 mutants show features of soma-to-germline transformation $[28,33]$. Soma-to-germline transformation is common to a number of transcriptional repressors, including the worm retinoblastoma homolog LIN-35, E2F components, and members of the worm NuRD complex, suggesting that HPL-2 may play a direct role in maintaining germline genes in a repressive chromatin state $[28,33]$.

The altered levels of lipid metabolic enzyme transcripts in $h p l-2$ mutants may represent an additional mechanism relevant to the observed lifespan increase. HPL-2 regulates the expression of genes involved in fatty acid and phospholipid metabolism. In mammals, glucose and lipid homeostasis in almost all major metabolic tissues is regulated in response to nutrient availability by the activity of the histone deacetylases SIRT1 [86]. Overexpression of the SIRT1 homolog Sir2 extends lifespan in Saccharomyces cerevisiae, C. elegans and Drosophila [87-89], possibly by altering lipid homeostasis through the conserved lipid/cholesterol regulator SREBP [90,91]. Our data suggest that HPL-2 may regulate phospholipid metabolism through regulation of two key enzymes: the sphingomyelin synthase gene sms-3 and the ceramide synthase lagr1. Expression of $s m s-3$ may be directly up-regulated by HPL-2, as we are able to detect HPL-2 binding to the sms-3 coding region. This association is consistent with growing evidence suggesting that HP1 proteins can also play positive roles in transcription through binding within gene bodies $[5,11,13,92]$.

Reduced expression of $s m s-3$ and lagr 1 in the absence of HPL-2 is associated with a $60 \%$ reduction in SM levels. Sphingolipids, including SM and its precursor ceramide, are cellular membrane components found in all eukaryotes and implicated in numerous functions, including the cellular response to environmental stresses and ageing [75,93-95]. In yeast, the ceramide synthase component LAG1 was one of the first longevity genes characterized [96], and subtle changes in ceramide/ sphingolipid metabolism are important in determining yeast longevity [97]. lagr-1 encodes one of three C. elegans orthologues of yeast LAG1. lagr-1(RNAi) results in reduced fat content and suppresses alpha-synuclein inclusions in living and aging animals, a phenotype associated with increased longevity [98]. Although neither lagr-1 nor sms-3 loss of function alone is associated with increased longevity [99] (FP and YX, data not 
shown), decreasing expression of hyl-1, another worm homolog of LAG1, increases longevity [99,100], and this effect is enhanced in hyl-1;lagr-1 double mutants ( $\mathrm{N}$ Faergeman, personal communication). Therefore, altered phospholipid metabolism in the absence of $h p l-2$ activity might contribute directly to the longevity phenotype associated with $h p l-2$ mutant animals.

Taken together, our results highlight the importance of epigenetic regulation in the maintenance of homeostasis. As an epigenetic regulator, $h p l-2 / \mathrm{HP} 1$ could both stabilize developmental decisions by buffering environmental variation, as well as guide the organism through remodeling events such as dauer that require plasticity of cell fate regulation. The signaling pathways that link HPL-2 to environmental cues are under investigation.

\section{Conclusions}

C. elegans provides an optimal system to explore the roles of HP1 beyond centromeric heterochromatin because worm chromosomes are holocentric and lack the alpha satellite repeats that nucleate the binding of HP1 to centromeres in other species. We have compared expression profiles of wild-type worms and worms lacking HLP-2, one of this organism's two HP1 homologues, at two developmental stages. We find that HPL-2 regulates the expression of germline genes, extracellular matrix components and genes involved in lipid metabolism. We show that in the soma, HPL-2 is involved in the dauer developmental decision, which is tightly linked to environmental conditions. We further uncover a novel function for HP1-regulated gene expression in longevity and lipid homeostasis. These pathways share the characteristic of responding to environmental cues. We suggest that HPL-2 influences the expression of genes that regulate developmental processes in response to environmental conditions.

\section{Materials and methods}

\section{Strains and genetics}

Strains were maintained according to the standard protocol [101]. The following mutant alleles and transgenic strains were used: LGI, daf-16(mu86); LGIII, $h p l-2$ (tm1489), daf-2(e1370), daf-7(e1372); LGIV, zIs356 (daf16::gfp). The Bristol strain N2 was used as wild type. To construct the hpl-2(tm1489); zIs356 (daf-16::gfp) strain, zIs356 (daf-16::gfp) hermaphrodites were mated with hpl-2 (tm1489) males. F2 worms were screened for the presence of GFP, and the presence of the $h p l-2$ deletion allele was confirmed by PCR analysis as previously described [23].

\section{Isolation of RNA for microarray analysis}

Wild-type and hpl-2(tm1489) gravid adult animals were synchronized by bleaching. Half of the culture was collected immediately for RNA extraction from the embryos. The other half was left to hatch overnight in M9 without food. Synchronized L1 larvae were then distributed onto peptone plates, grown at $20^{\circ} \mathrm{C}$ and staged until they reached the L3 larval stage (between 28 and 29 hours). The developmental stage was confirmed by microscopic observation, using both vulval development and somatic gonad development as criteria.

Triple biological replicates were flash frozen in liquid N2 and RNA was extracted using the standard Trizol method followed by RNeasy column purification (Qiagen, France, \#74104). RNA was labeled and hybridized to Affymetrix tiling arrays. Washing and scanning were performed following the manufacturer's instructions. Oligos from the tiling array were mapped to chromosome coordinates of the exons from Wormbase WS180. Any oligo that mapped to a gene on both the Watson and Crick strands was excluded. The remaining oligos were then grouped together (perfect match and mismatch) into probe sets and written out into an Affymetrix CDF file. The CDF file was converted into an R-package and loaded into R. The expression values were calculated using the justRMA function from Bioconductor. This used a Benjamini and Hochberg false discovery rate correction. The $\mathrm{R}$ code is available upon request.

\section{Quantitative PCR on reverse transcription products}

cDNAs were synthesized with a mix of random hexamers and oligo dT primers using iScript cDNA synthesis kit and 500 ng of RNA (BIO-RAD, France). qPCR reactions on reverse transcription products diluted ten times were performed using FastStart Universal SYBR Green Master (Roche, France) and the StepOne Plus Detection System (Applied Biosystems, France). The qPCR conditions were $95^{\circ} \mathrm{C}$ for 4 minutes, followed by 40 cycles of $12 \mathrm{~s}$ at $95^{\circ} \mathrm{C}$ and $30 \mathrm{~s}$ at $60^{\circ} \mathrm{C}$. Melting curve analysis was performed for each primer set at the end to ensure the specificity of the amplified product. Standard curves were generated for each primer set to calculate the efficiency of each set. Only primer sets with an efficiency between 1.9 and 2.1 were used for qPCR. Primer sets for the pmp-3 and $c d c-42$ transcripts were used as internal controls, and the RNA level of each gene of interest was normalized to the level of the mean of both these genes for comparison. qPCR experiments were repeated at least three times using independent RNA/cDNA preparations. Data were pooled and analyzed using the StepOne Plus Software (Applied Biosystems). Primer sequences are available upon request.

\section{Comparisons of different microarray datasets}

The $P$-values for overlaps between lists were generated by comparison to results of random simulation and by 
calculation based on the hypergeometric distribution as in [102], using R.

\section{Construction of transgenic lines}

For intestinal expression, the $\mathrm{hpl}-2$ (K01G5.2a) fulllength cDNA was cloned into the XbaI-SacII sites of pJM16 under the control of the ges-1 promoter [103]. For pan-neuronal expression, the cDNA was cloned into the NotI-SmaI sites of pHU004, under the control of the $r a b-3$ promoter in fusion with GFP (gift from JL Bessereau). Both intestinal-specific and neuronal-specific constructs, named pCB15 and pSS05, respectively, were injected into N2 hermaphrodites at a concentration of 5 $\mathrm{mg} / \mathrm{ml}$ using pRF4 as a co-transformation marker at a concentration of $200 \mathrm{mg} / \mathrm{ml}$. For each construct, two to three independent transgenic lines were then crossed with hpl-2(tm1489);daf-2(e1370) males. F2 rollers were allowed to lay eggs at $15^{\circ} \mathrm{C}$, then shifted to $25^{\circ} \mathrm{C}$. The $\mathrm{F} 3$ were selected for both $100 \%$ dauer in the progeny and the presence of the $h p l-2$ deletion allele.

\section{Lifespan assay}

Lifespan tests were performed at $20^{\circ} \mathrm{C}$ as described in [104]. For each genotype, lifespan experiments were repeated two to four times. Survival analysis was carried out using the Kaplan Meier method and the significance of differences between survival curves calculated using the log rank test. The statistical software used was XLSTAT 2007 and all $P$-values $<0.05$ were considered significant.

\section{Chromatin immunoprecipitation}

The ChIP protocol was based on [105], with a number of modifications. L3 staged wild-type or transgenic animals carrying an integrated rescuing $h p l-2::$ GFP construct [23] were used as starting material. Worm powder was incubated in phosphate-buffered saline containing $1.5 \mathrm{mM}$ EGS for 20 minutes at room temperature, followed by the addition of formaldehyde ( $1 \%$ final) for 10 minutes at room temperature. After quenching with glycine (125 $\mathrm{mM}$ final), the worm pellet was washed in phosphatebuffered saline, resuspended in lysis buffer $(50 \mathrm{mM}$ HEPES/KOH pH 7.6, 1 mM EDTA, 0.5\% sarkosyl, 150 $\mathrm{mM} \mathrm{KCl}$, protease inhibitors cocktail (Roche Biochemicals) and $1 \mathrm{mM} \mathrm{PMSF}$ ) and sonicated in a Bioruptor water bath (Diagenode, Belgium). The homogenate was centrifuged at $12,000 \mathrm{rpm}$ for 15 minutes at $4{ }^{\circ} \mathrm{C}$ and the supernatant containing the sheared chromatin (chromatin extract) precleared twice for 30 minutes at $4^{\circ} \mathrm{C}$ with $80 \mu \mathrm{l}$ of a 1:1 slurry of protein A agarose beads (Millipore \#16157, France). The cleared extract was diluted with 2 volumes of FA buffer (50 mM HEPES/KOH pH 7.5, 1 mM EDTA, $1 \%$ Triton X-100, $0.1 \%$ sodium deoxycholate, $150 \mathrm{mM} \mathrm{KCl}$, protease inhibitors cocktail and $1 \mathrm{mM}$
PMSF). Following incubation with antibodies (anti-HPL2 or anti-GFP), $45 \mu \mathrm{l}$ of a 1:1 slurry of protein A agarose beads was added to each tube for 1 hour. Beads were washed twice with FA buffer, once with FA-500 $(50 \mathrm{mM}$ HEPES/KOH pH 7.5, 1 mM EDTA, 1\% Triton X-100, $0.1 \%$ sodium deoxycholate, $500 \mathrm{mM} \mathrm{NaCl}$ ), once with FA-1M (50 mM HEPES/KOH pH 7.5, 1 mM EDTA, 1\% Triton X-100, $0.1 \%$ sodium deoxycholate, $1 \mathrm{M} \mathrm{NaCl}$ ), once with TEL $(0.25 \mathrm{M} \mathrm{LiCl}, 1 \% \mathrm{NP}-40,1 \%$ sodium deoxycholate, $1 \mathrm{mM}$ EDTA, $10 \mathrm{mM}$ Tris- $\mathrm{HCl}$, $\mathrm{pH}$ 8.0), and twice with TE (10 mM Tris/HCl, $1 \mathrm{mM}$ EDTA). Elution was performed by adding two times $100 \mu$ l of elution buffer (10 mM Tris/HCl, $1 \mathrm{mM}$ EDTA, $250 \mathrm{mM} \mathrm{NaCl}$, $1 \%$ SDS) and incubating at $65^{\circ} \mathrm{C}$ for 10 minutes. Supernatants were pooled, incubated for 30 minutes with $1 \mu \mathrm{l}$ of RNase A $(10 \mathrm{mg} / \mathrm{ml})$ and then incubated overnight at $65^{\circ}$ $\mathrm{C}$ with $1 \mu \mathrm{l}$ of proteinase $\mathrm{K}$ ( 15 to $20 \mathrm{mg} / \mathrm{ml}$ ). DNA was recovered using a Qiaquick pure purification kit in $40 \mu \mathrm{l}$ of PCR grade water for qPCR analysis. ChIP results were analyzed by qPCR using primers specific to the sms-3 locus. A primer corresponding to an intergenic region on chromosome IV was used as control. The anti-GFP antibody used was from Abcam, UK (\#ab290).

\section{Lipid extraction and analysis}

The solid phase extraction procedure was performed as previously described [74]. Briefly, lipids were extracted using the Folch procedure [106] and loaded onto a 100 mg aminopropyl LC-NH2 cartridge pre-equilibrated with $3 \mathrm{ml}$ of hexane, and placed onto a vacuum manifold apparatus (12 port Visiprep, Supelco, SigmaAldrich, France). Neutral lipids (sterols, sterol esters, methylated fatty acids, tri- and diacylglicerides; fraction 1) were eluted with $1.4 \mathrm{ml}$ hexane:ethylacetate $(85: 15 \mathrm{v} /$ v) at a solvent flow rate of $0.3 \mathrm{ml} /$ minute obtained by applying negative pressure. Ceramides (fraction 2) were eluted with $1.6 \mathrm{ml}$ of chloroforme:methanol $(23: 1 \mathrm{v} / \mathrm{v})$. Free fatty acids (fraction 3) were eluted with $1.8 \mathrm{ml}$ diisopropylether-acetic acid $(98: 5, \mathrm{v} / \mathrm{v})$, and this fraction was pooled together with fraction 1. Glycosphingolipids (fraction 4) were eluted using $2.1 \mathrm{ml}$ of acetone-methanol $(9: 1.35, \mathrm{v} / \mathrm{v})$. Neutral and acidic phospholipids were eluted together in one fraction (fraction 5) using $2 \mathrm{ml}$ of methanol. The fractions were dried under $\mathrm{N}_{2}$ and resolved by thin layer chromatography using the following solvent systems: for separation of neutral lipids and free fatty acids, hexane:diethylether:acetic acid (80:20:1 $\mathrm{v} / \mathrm{v} / \mathrm{v})$; for ceramides, chloroform:methanol $(50: 5 \mathrm{v} / \mathrm{v})$; for glycosphingolipids, chloroform:methanol:water $(65: 25: 4 \mathrm{v} / \mathrm{v} / \mathrm{v})$; for resolution of phospholipids by twodimensional thin layer chromatography, tetrahydrofurane:acetone:methanol:water $(50: 20: 40: 6 \mathrm{v} / \mathrm{v} / \mathrm{v} / \mathrm{v})$ in the first direction and chloroform:acetone:methanol:aceticacid:water in the second direction (50:20:10:15:5 v/v/v/v/ 
v). Fractions 1, 2, 3 and 4 were detected after spraying with cupric sulfate and charred at $180^{\circ} \mathrm{C}$ for 5 minutes. Phospholipids were detected by iodine and scraped into glass tubes. Lipidic phosphorous was mineralized by warming the samples in $0.25 \mathrm{ml}$ mixture of sulfuric acid:perchloric acid $(2: 1 \mathrm{v} / \mathrm{v})$ containing vanadium tetraoxide $(1 \mathrm{~g} / \mathrm{l})$ for $20 \mathrm{~s}$ above the flame and quantified by $5 \mathrm{ml}$ of reagent containing $0.63 \mathrm{~g}$ of ANSA mixture, 0.2 $\mathrm{g}$ ammonium heptamolybdate in $100 \mathrm{ml}$ of water (ANSA contains $60 \mathrm{~g}$ of sodium metabisulfate, $2 \mathrm{~g}$ of sodium sulfate and $1 \mathrm{~g}$ of 1-amino 2-naphtol 4-sulfonic acid). Samples were mixed by vortexing, incubated at $100^{\circ} \mathrm{C}$ for 8 minutes and absorbances were read at 830 $\mathrm{nm}$. Standard curves were made by the use of monopotassium phosphate.

\section{Data availability}

Microarray data are publicly available through NCBI, Gene Expression Omnibus accession number [GSE33700].

\section{Additional material}

Additional file 1: Differentially expressed genes for embryos and L3 stage larvae in wild type compared to $\mathrm{hpl}-2$ mutant animals. Additional file 2: Increased lin-13::GFP expression in the absence of HPL-2 activity. Expression of a lin-13::GFP translational fusion [108] in wild-type and hpl-2 mutant animals. In hpl-2 mutant animals GFP expression was particularly strong in nuclei in the head region (arrows).

Additional file 3: HPL-2 regulation of specific gene classes. (a-f) Venn diagrams showing overlap between: (a) genes up-regulated in L3 stage $\mathrm{hpl} / 2$ mutants and germline genes; (b) genes down-regulated in L3 stage hpl-2 mutants and genes induced in dauer exit; (c) genes downregulated in L3 stage hpl-2 mutants and genes clustered in expression mountain 29 of the C. elegans three-dimensional topographical expression map; (d) genes regulated in L3 stage hpl-2 mutants and neuronally expressed genes; (e) genes down-regulated in L3 stage hpl-2 mutants and daf-16 target genes; ( $f$ ) genes down-regulated in L3 stage $h p l-2$ mutants and aging regulated genes.

Additional file 4: Overlap between $\mathrm{hpl}$-2-regulated genes and genes bound by HPL-2. Venn diagram showing overlap between genes regulated in L3 stage hpl-2 mutants and genes bound by HPL-2 [29].

Additional file 5: HPL-2 and $\mathrm{H} 3 \mathrm{~K} 9 \mathrm{me} 3$ are enriched on repetitive transgenes. (a) Histogram representing the percentage of immunoprecipitation, calculated as the ratio between signal from the antibodies and signal from pre-immune serum, from ChIP experiments along a repetitive transgene. Synchronized populations of L3 wild-type or hpl-2 mutant worms carrying the trangene were subjected to immunoprecipitation using anti-HPL-2, anti-H3K9me3, or pre-immune serum as control. (b) Schematic representation of the transgene used in these experiments [109] showing the position of the primers used for qPCR analysis. Similar results were obtained for three to four independent experiments.

Additional file 6: Repressive histone mark levels on promoters and genes misregulated in $\mathbf{h p l - 2}$ mutant worms. For each gene or gene promoter, H3K9 mono-, di- and tri-methyl levels were calculated as the median level observed on the DNA stretch using data provided by the modENCODE Consortium [29]. The criterion for choosing control genes was similar expression levels. Data are presented as box-whisker representation where the bar indicates the median of all up- or downregulated genes and the upper and lower edges of the box represent the 25th and 75th percentiles, respectively. Up-regulated genes show a significantly higher level of mono-, di- and tri-methylated H3K9, but no enrichment in H3K27 trimethylation, compared to expression-matched control genes. Down-regulated genes show a similar level of mono-, diand tri-methylated H3K9 compared to expression-matched control genes.

Additional file 7: rab-3p::hpl-2cDNA::GFP transgene is expressed uniquely in neuronal cells. GFP fluorescence is detected in the synaptic-rich regions of the nervous system, including the nerve ring, ventral nerve cord, and dorsal nerve cord (arrowheads).

Additional file 8: Increased lifespan of $h p l-2$ (RNAi) animals. Animals at the $L 4$ stage were placed on RNAi or control bacteria at $20^{\circ} \mathrm{C}$ and allowed to lay eggs. When $\mathrm{F} 1$ progeny reached the $\mathrm{L} 4$ stage, they were transferred to $25^{\circ} \mathrm{C}$ for lifespan assays on plates containing $10 \mu \mathrm{M} 5 \mathrm{FU}$. Worms were then transferred to fresh RNAi plates every week. hpl-2 RNAi increased average lifespan by 18\% (average lifespans: wild type fed control bacteria, $10.3 \pm 0.42(n=60)$; wild type fed $h p l-2$ RNAi clone 1 , $12.2 \pm 0.32$ days $\left(n=60\right.$; control comparison $\left.P=10^{-3}\right)$. Similar results were obtained in two independent tests.

Additional file 9: $\mathrm{hpl}-2$ deletion does not affect the total number of germ cells produced. Data are displayed as the mean ( \pm standard deviation) number of germ cells per gonad arm $(n=4)$. Germ cell number was obtained by counting germ cell nuclei stained with DAPI in dissected gonads of young adults.

Additional file 10: $\mathrm{hpl}-2$ does not influence DAF-16::GFP localization Adults carrying a daf-16::gfp transgene (z/s356) were placed on NGM plates at $37^{\circ} \mathrm{C}$. After 45 minutes, worms were mounted onto a slide in M9 buffer. Nuclear translocation of DAF-16::GFP was visualized with a fluorescence microscope Axiolmager Z1 (Zeiss) equipped with a CoolSnap HQ camera and driven by Metamorph software (Molecular Devices, France).

Additional file 11: The $h p l-2(t m 1489)$ deletion mutant does not affect resistance to oxidative stress. Adult hermaphrodites were incubated in M9 buffer with $100 \mathrm{mM}$ paraquat. After incubation at $20^{\circ} \mathrm{C}$ for the specified duration, survival was measured. Worms were scored as dead when they did not respond to a mechanical stimulus. The experiment was performed three times. Mean fraction alive indicates the average survival among the multiple trials and the error bar represents the standard deviation. P-value was calculated using Student's $t$-test.

Additional file 12: $h p l-2$ does not influence levels of ceramides and neutral lipids. (a) Ceramides (elution fraction 2) isolated from wild-type and $\mathrm{hpl}-2$ animals were loaded on thin layer chromatography plates and run in a chloroform:methanol (50:5) solvent system. (b) Neutral lipids (elution fraction 1 and 3) were deposited on thin layer chromatography plates and run in hexane:diisopropylether:acetic acid (80:20:1).

\section{Abbreviations}

ChIP: chromatin immunoprecipitation; FET: Fisher exact test; GFP: green fluorescent protein; GO: Gene Ontology; H3K9: histone H3 lysine 9; H3K9me3: tri-methylated lysine 9 of histone H3; Hh: Hedgehog; Hp: Heterochromatin protein; IIR: insulin/insulin-like growth factor--like receptor; PC: phosphatidylcholine; PE: phosphatidylethanolamine; PMSF: phenylmethanesulfonylfluoride; PS: phosphatidylserine; qPCR: quantitative PCR; qRT-PCR: quantitative reverse-transcriptase PCR; RNAi: RNA interference; SM: sphingomyelin; TGF: transforming growth factor.

\section{Acknowledgements}

Thanks to E Oakeley and T Roloff of the FMl for help in designing microarray experiments and data analysis, J Alcedo for providing dauer pheromone extract, Y Kohara for cDNA clones, JD McGhee and JL Bessereau for reagents and the Caenorhabditis Genetic Center, which is supported by the National Center for Research, for strains. Thanks to S Kueng for critical reading of the manuscript.

\section{Author details}

${ }^{1}$ Friedrich Miescher Institute for Biomedical Research, Maulbeerstrasse 66, 4058 Basel, Switzerland. ${ }^{2}$ Cell Fate and Nuclear Organization, Institute of Cell Biology, University of Bern, Baltzerstrasse 6, CH-3012 Bern, Switzerland. 
${ }^{3}$ Laboratory of Molecular and Cellular Biology, CNRS, Université de Lyon, Ecole Normale Supérieure, 69364 Lyon Cedex 07, France. ${ }^{4}$ Development Biology Institute of Marseille Luminy, UMR 6216, Case 907 - Parc Scientifique de Luminy, 13288 Marseille Cedex 9, France. ${ }^{5}$ Center of Molecular and Cellular Physiology and Genetics, Université Lyon 1, CNRS UMR 5534, 69622 Villeurbanne, France.

\section{Authors' contributions}

PM participated in the design of the study, analyzed the data, performed the statistical analysis, and helped to draft the manuscript. SS carried out genetic analysis. $\mathrm{CB}$ and $\mathrm{BH}$ carried out the molecular analysis. YX carried out the molecular analysis and the lipid analysis. LM and FS carried out the longevity assays. SB carried out the lipid analysis. SG helped draft the manuscript. FP conceived the study, participated in its design and coordination and drafted the manuscript. All authors read and approved the final manuscript for publication.

\section{Competing interests}

The authors declare that they have no competing interests.

Received: 11 July 2011 Revised: 30 November 2011

Accepted: 20 December 2011 Published: 20 December 2011

\section{References}

1. Bannister AJ, Zegerman P, Partridge JF, Miska EA, Thomas JO, Allshire RC, Kouzarides T: Selective recognition of methylated lysine 9 on histone $\mathrm{H} 3$ by the HP1 chromo domain. Nature 2001, 410:120-124.

2. Lachner $M, O^{\prime}$ Carroll $D$, Rea $S$, Mechtler $K$, Jenuwein T: Methylation of histone H3 lysine 9 creates a binding site for HP1 proteins. Nature 2001, 410:116-120.

3. Dialynas GK, Vitalini MW, Wallrath LL: Linking Heterochromatin protein 1 (HP1) to cancer progression. Mutat Res 2008, 647:13-20.

4. Pidoux AL, Allshire RC: Kinetochore and heterochromatin domains of the fission yeast centromere. Chromosome Res 2004, 12:521-534.

5. de Wit E, Greil F, van Steensel B: High-resolution mapping reveals links of HP1 with active and inactive chromatin components. PLOS Genet 2007, 3: e38.

6. Li Y, Kirschmann DA, Wallrath LL: Does heterochromatin protein 1 always follow code? Proc Natl Acad Sci USA 2002, 99(Suppl 4):16462-16469.

7. Hediger F, Gasser SM: Heterochromatin protein 1: don't judge the book by its cover! Curr Opin Genet Dev 2006, 16:143-150.

8. Lin CH, Li B, Swanson S, Zhang Y, Florens L, Washburn MP, Abmayr SM, Workman JL: Heterochromatin protein 1a stimulates histone H3 lysine 36 demethylation by the Drosophila KDM4A demethylase. Mol Cell 2008, 32:696-706.

9. Font-Burgada J, Rossell D, Auer H, Azorin F: Drosophila HP1C isoform interacts with the zinc-finger proteins WOC and Relative-of-WOC to regulate gene expression. Genes Dev 2008, 22:3007-3023.

10. Piacentini L, Fanti L, Negri R, Del Vescovo V, Fatica A, Altieri F, Pimpinelli S Heterochromatin protein 1 (HP1a) positively regulates euchromatic gene expression through RNA transcript association and interaction with hnRNPs in Drosophila. PLoS Genet 2009, 5:e1000670.

11. Kwon SH, Florens L, Swanson SK, Washburn MP, Abmayr SM, Workman JL Heterochromatin protein 1 (HP1) connects the FACT histone chaperone complex to the phosphorylated CTD of RNA polymerase II. Genes Dev 24:2133-2145

12. Ogawa H, Ishiguro K, Gaubatz S, Livingston DM, Nakatani Y: A complex with chromatin modifiers that occupies E2F- and Myc-responsive genes in G0 cells. Science 2002, 296:1132-1136.

13. Vakoc CR, Mandat SA, Olenchock BA, Blobel GA: Histone H3 lysine 9 methylation and HP1gamma are associated with transcription elongation through mammalian chromatin. Mol Cell 2005, 19:381-391.

14. Saint-Andre V, Batsche E, Rachez C, Muchardt C: Histone H3 lysine 9 trimethylation and HP1 gamma favor inclusion of alternative exons. Nat Struct Mol Biol 2011, 18:337-U127.

15. Kellum R, Alberts BM: Heterochromatin protein 1 is required for correct chromosome segregation in Drosophila embryos. J Cell Sci 1995, 108:1419-1431.

16. Liu LP, Ni JQ, Shi YD, Oakeley EJ, Sun FL: Sex-specific role of Drosophila melanogaster HP1 in regulating chromatin structure and gene transcription. Nat Genet 2005, 37:1361-1366.
17. Agarwal N, Hardt T, Brero A, Nowak D, Rothbauer U, Becker A, Leonhardt H, Cardoso MC: MeCP2 interacts with HP1 and modulates its heterochromatin association during myogenic differentiation. Nucleic Acids Res 2007, 35:5402-5408.

18. Takanashi M, Oikawa K, Fujita K, Kudo M, Kinoshita M, Kuroda M: Heterochromatin protein 1gamma epigenetically regulates cell differentiation and exhibits potential as a therapeutic target for various types of cancers. Am J Pathol 2009, 174:309-316.

19. Cammas F, Janoshazi A, Lerouge T, Losson R: Dynamic and selective interactions of the transcriptional corepressor TIF1 beta with the heterochromatin protein HP1 isotypes during cell differentiation. Differentiation 2007, 75:627-637.

20. Panteleeva I, Boutillier S, See V, Spiller DG, Rouaux C, Almouzni G, Bailly D, Maison C, Lai HC, Loeffler JP, Boutillier AL: HP1alpha guides neuronal fate by timing E2F-targeted genes silencing during terminal differentiation. EMBO J 2007, 26:3616-3628.

21. Ritou E, Bai M, Georgatos SD: Variant-specific patterns and humoral regulation of HP1 proteins in human cells and tissues. J Cell Sci 2007, 120:3425-3435.

22. Couteau F, Guerry F, Muller F, Palladino F: A heterochromatin protein 1 homologue in Caenorhabditis elegans acts in germline and vulval development. EMBO Rep 2002, 3:235-241.

23. Coustham V, Bedet C, Monier K, Schott S, Karali M, Palladino F: The C. elegans HP1 homologue HPL-2 and the LIN-13 zinc finger protein form a complex implicated in vulval development. Dev Biol 2006, 297:308-322.

24. Schott S, Coustham V, Simonet T, Bedet C, Palladino F: Unique and redundant functions of $C$. elegans HP1 proteins in post-embryonic development. Dev Biol 2006, 298:176-187.

25. Yuen KW, Nabeshima K, Oegema K, Desai A: Rapid de novo centromere formation occurs independently of heterochromatin protein 1 in C. elegans embryos. Curr Biol 2011, 211:1800-1807.

26. Schott S, Ramos F, Coustham V, Palladino F: HPL-2/HP1 prevents inappropriate vulval induction in Caenorhabditis elegans by acting in both HYP7 and vulval precursor cells. Genetics 2009, 181:797-801.

27. Curran $S P, W u X$, Riedel $C G$, Ruvkun $G$ : A soma-to-germline transformation in long-lived Caenorhabditis elegans mutants. Nature 2009, 459:1079-1084.

28. Petrella LN, Wang W, Spike CA, Rechtsteiner A, Reinke V, Strome S: synMuv $B$ proteins antagonize germline fate in the intestine and ensure $C$. elegans survival. Development 2011, 138:1069-1079.

29. modENCODE. [http://www.modENCODE.org].

30. Fielenbach N, Antebi A: C. elegans dauer formation and the molecular basis of plasticity. Genes Dev 2008, 22:2149-2165.

31. Cryderman DE, Grade SK, Li Y, Fanti L, Pimpinelli S, Wallrath LL: Role of Drosophila HP1 in euchromatic gene expression. Dev Dyn 2005, 232:767-774.

32. Piacentini L, Pimpinelli S: Positive regulation of euchromatic gene expression by HP1. Fly (Austin) 2010, 4:299-301.

33. Wang D, Kennedy S, Conte D Jr, Kim JK, Gabel HW, Kamath RS, Mello CC, Ruvkun G: Somatic misexpression of germline P granules and enhanced RNA interference in retinoblastoma pathway mutants. Nature 2005, 436:593-597.

34. Robert VJ, Sijen T, van Wolfswinkel J, Plasterk RH: Chromatin and RNAi factors protect the $C$. elegans germline against repetitive sequences. Genes Dev 2005, 19:782-787.

35. Kim SK, Lund J, Kiraly M, Duke K, Jiang M, Stuart JM, Eizinger A, Wylie BN, Davidson GS: A gene expression map for Caenorhabditis elegans. Science 2001, 293:2087-2092.

36. Fanti L, Pimpinelli S: HP1: a functionally multifaceted protein. Curr Opin Genet Dev 2008, 18:169-174.

37. Kelly WG, Schaner CE, Dernburg AF, Lee MH, Kim SK, Villeneuve AM, Reinke V: X-chromosome silencing in the germline of $C$. elegans. Development 2002, 129:479-492.

38. Bessler JB, Andersen EC, Villeneuve AM: Differential localization and independent acquisition of the H3K9me2 and H3K9me3 chromatin modifications in the Caenorhabditis elegans adult germ line. PLoS Genet 6:e1000830.

39. Liu T, Zimmerman KK, Patterson Gl: Regulation of signaling genes by TGFbeta during entry into dauer diapause in C. elegans. BMC Dev Biol 2004, 4:11.

40. Hu PJ: Dauer. WormBook 2007, 1-19. 
41. Wang J, Kim SK: Global analysis of dauer gene expression in Caenorhabditis elegans. Development 2003, 130:1621-1634.

42. Novelli J, Ahmed S, Hodgkin J: Gene interactions in Caenorhabditis elegans define DPY-31 as a candidate procollagen C-proteinase and SQT-3/ROL-4 as its predicted major target. Genetics 2004, 168:1259-1273.

43. Park JO, Pan J, Mohrlen F, Schupp M, Johnsen R, Baillie DL, Zapf R, Moerman DG, Hutter H: Characterization of the astacin family of metalloproteases in C. elegans. BMC Dev Biol 10:14.

44. Kolotuev I, Apaydin A, Labouesse M: Secretion of Hedgehog-related peptides and WNT during Caenorhabditis elegans development. Traffic 2009, 10:803-810.

45. Zugasti O, Rajan J, Kuwabara PE: The function and expansion of the Patched- and Hedgehog-related homologs in C. elegans. Genome Res 2005, 15:1402-1410.

46. Burglin TR, Kuwabara PE: Homologs of the Hh signalling network in $C$. elegans. WormBook 2006, 1-14.

47. Page A, Johnstone I: The cuticle. WormBook 2007, 1-15.

48. Jeong PY, Kwon MS, Joo HJ, Paik YK: Molecular time-course and the metabolic basis of entry into dauer in Caenorhabditis elegans. PLOS One 2009, 4:e4162.

49. Dauer Metabolic Database. [http://dauerdb.org]

50. Riddle DL, Swanson MM, Albert PS: Interacting genes in nematode dauer larva formation. Nature 1981, 290:668-671.

51. Lee SS, Kennedy S, Tolonen AC, Ruvkun G: DAF-16 target genes that control C. elegans life-span and metabolism. Science 2003, 300:644-647.

52. Swanson MM, Riddle DL: Critical periods in the development of the Caenorhabditis elegans dauer larva. Dev Biol 1981, 84:27-40.

53. Apfeld J, Kenyon C: Regulation of lifespan by sensory perception in Caenorhabditis elegans. Nature 1999, 402:804-809.

54. Wolkow CA, Kimura KD, Lee MS, Ruvkun G: Regulation of C. elegans lifespan by insulinlike signaling in the nervous system. Science 2000, 290:147-150.

55. Libina N, Berman JR, Kenyon C: Tissue-specific activities of C. elegans DAF16 in the regulation of lifespan. Cell 2003, 115:489-502.

56. Russell SJ, Kahn CR: Endocrine regulation of ageing. Nat Rev Mol Cell Biol 2007, 8:681-691.

57. Murphy $C T$, McCarroll SA, Bargmann Cl, Fraser A, Kamath RS, Ahringer J, $\mathrm{Li} \mathrm{H}$, Kenyon C: Genes that act downstream of DAF-16 to influence the lifespan of Caenorhabditis elegans. Nature 2003, 424:277-283.

58. Budovskaya $\mathrm{W}$, Wu K, Southworth $L K$, Jiang $M$, Tedesco $P$, Johnson $T E$, Kim SK: An elt-3/elt-5/elt-6 GATA transcription circuit guides aging in C. elegans. Cell 2008, 134:291-303.

59. Calnan DR, Brunet A: The FoxO code. Oncogene 2008, 27:2276-2288.

60. Henderson ST, Johnson TE: daf-16 integrates developmental and environmental inputs to mediate aging in the nematode Caenorhabditis elegans. Curr Biol 2001, 11:1975-1980.

61. Van Raamsdonk JM, Hekimi S: Deletion of the mitochondrial superoxide dismutase sod-2 extends lifespan in Caenorhabditis elegans. PLOS Genet 2009, 5:e1000361.

62. Fujii M, Matsumoto Y, Tanaka N, Miki K, Suzuki T, Ishii N, Ayusawa D: Mutations in chemosensory cilia cause resistance to paraquat in nematode Caenorhabditis elegans. J Biol Chem 2004, 279:20277-20282.

63. Wolff $\mathrm{S}, \mathrm{Ma} H$, Burch D, Maciel GA, Hunter T, Dillin A: SMK-1, an essential regulator of DAF-16-mediated longevity. Cell 2006, 124:1039-1053.

64. Li J, Ebata A, Dong Y, Rizki G, Iwata T, Lee SS: Caenorhabditis elegans HCF1 functions in longevity maintenance as a DAF-16 regulator. PLOS Biol 2008, 6:e233.

65. Hsu AL, Murphy CT, Kenyon C: Regulation of aging and age-related disease by DAF-16 and heat-shock factor. Science 2003, 300:1142-1145.

66. Walker GA, Lithgow GJ: Lifespan extension in C. elegans by a molecular chaperone dependent upon insulin-like signals. Aging Cell 2003, 2:131-139

67. Melov S, Golden TR: Gene expression changes associated with aging in C. elegans. WormBook 2007, 1-12

68. Bluher M, Kahn BB, Kahn CR: Extended longevity in mice lacking the insulin receptor in adipose tissue. Science 2003, 299:572-574.

69. Giannakou ME, Goss M, Junger MA, Hafen E, Leevers SJ, Partridge L: Longlived Drosophila with overexpressed dFOXO in adult fat body. Science 2004, 305:361
70. Hwangbo DS, Gershman B, Tu MP, Palmer M, Tatar M: Drosophila dFOXO controls lifespan and regulates insulin signalling in brain and fat body. Nature 2004, 429:562-566.

71. Wang MC, O'Rourke EJ, Ruvkun G: Fat metabolism links germline stem cells and longevity in C. elegans. Science 2008, 322:957-960.

72. McKay RM, McKay JP, Avery L, Graff JM: C elegans: a model for exploring the genetics of fat storage. Dev Cell 2003, 4:131-142.

73. O'Rourke EJ, Soukas AA, Carr CE, Ruvkun G: C. elegans major fats are stored in vesicles distinct from lysosome-related organelles. Cell Metab 2009, 10:430-435.

74. Bodennec J, Koul O, Aguado I, Brichon G, Zwingelstein G, Portoukalian J: A procedure for fractionation of sphingolipid classes by solid-phase extraction on aminopropyl cartridges. J Lipid Res 2000, 41:1524-1531.

75. Hannun YA, Obeid LM: Principles of bioactive lipid signalling: lessons from sphingolipids. Nat Rev Mol Cell Biol 2008, 9:139-150.

76. Hall SE, Beverly M, Russ C, Nusbaum C, Sengupta P: A cellular memory of developmental history generates phenotypic diversity in C. elegans. Curr Biol 2010, 20:149-155.

77. Bargmann Cl, Horvitz HR: Control of larval development by chemosensory neurons in Caenorhabditis elegans. Science 1991, 251:1243-1246.

78. Albert PS, Riddle DL: Mutants of Caenorhabditis elegans that form dauerlike larvae. Dev Biol 1988, 126:270-293.

79. Hamilton B, Dong Y, Shindo M, Liu W, Odell I, Ruvkun G, Lee SS: A systematic RNAi screen for longevity genes in C. elegans. Genes Dev 2005, 19:1544-1555.

80. Greer EL, Maures TJ, Hauswirth AG, Green EM, Leeman DS, Maro GS, Han S, Banko MR, Gozani O, Brunet A: Members of the H3K4 trimethylation complex regulate lifespan in a germline-dependent manner in $C$. elegans. Nature 2010, 466:383-387.

81. Frankel S, Rogina B: Drosophila longevity is not affected by heterochromatin-mediated gene silencing. Aging Cell 2005, 4:53-56.

82. Wood JG, Hillenmeyer S, Lawrence C, Chang C, Hosier S, Lightfoot W, Mukherjee E, Jiang N, Schorl C, Brodsky AS, Neretti N, Helfand SL: Chromatin remodeling in the aging genome of Drosophila. Aging Cell 2010, 9:971-978.

83. Scaffidi P, Misteli T: Lamin A-dependent nuclear defects in human aging. Science 2006, 312:1059-1063.

84. McElwee JJ, Schuster E, Blanc E, Thomas JH, Gems D: Shared transcriptional signature in Caenorhabditis elegans Dauer larvae and long-lived daf-2 mutants implicates detoxification system in longevity assurance. J Biol Chem 2004, 279:44533-44543.

85. Halaschek-Wiener J, Khattra JS, MCKay S, Pouzyrev A, Stott JM, Yang GS, Holt RA, Jones SJ, Marra MA, Brooks-Wilson AR, Riddle DL: Analysis of longlived $C$. elegans daf-2 mutants using serial analysis of gene expression. Genome Res 2005, 15:603-615.

86. Yu J, Auwerx J: The role of sirtuins in the control of metabolic homeostasis. Ann N Y Acad Sci 2009, 1173(Suppl 1):E10-19.

87. Tissenbaum HA, Guarente L: Increased dosage of a sir-2 gene extends lifespan in Caenorhabditis elegans. Nature 2001, 410:227-230.

88. Rogina B, Helfand SL: Sir2 mediates longevity in the fly through a pathway related to calorie restriction. Proc Natl Acad Sci USA 2004, 101:15998-16003.

89. Wood JG, Rogina B, Lavu S, Howitz K, Helfand SL, Tatar M, Sinclair D: Sirtuin activators mimic caloric restriction and delay ageing in metazoans. Nature 2004, 430:686-689.

90. Purushotham A, Schug TT, Xu Q, Surapureddi S, Guo X, Li X: Hepatocytespecific deletion of SIRT1 alters fatty acid metabolism and results in hepatic steatosis and inflammation. Cell Metab 2009, 9:327-338.

91. Walker AK, Yang F, Jiang K, Ji JY, Watts JL, Purushotham A, Boss O, Hirsch ML, Ribich S, Smith JJ, Israelian K, Westphal CH, Rodgers JT, Shioda T, Elson SL, Mulligan P, Najafi-Shoushtari H, Black JC, Thakur JK, Kadyk LC, Whetstine JR, Mostoslavsky R, Puigserver P, Li X, Dyson NJ, Hart AC, Naar AM: Conserved role of SIRT1 orthologs in fasting-dependent inhibition of the lipid/cholesterol regulator SREBP. Genes Dev 2010, 24:1403-1417.

92. Piacentini L, Fanti L, Berloco M, Perrini B, Pimpinelli S: Heterochromatin protein 1 (HP1) is associated with induced gene expression in Drosophila euchromatin. J Cell Biol 2003, 161:707-714.

93. Jenkins GM: The emerging role for sphingolipids in the eukaryotic heat shock response. Cell Mol Life Sci 2003, 60:701-710. 
94. Cutler RG, Mattson MP: Sphingomyelin and ceramide as regulators of development and lifespan. Mech Ageing Dev 2001, 122:895-908.

95. Sacket SJ, Chung HY, Okajima F, Im DS: Increase in sphingolipid catabolic enzyme activity during aging. Acta Pharmacol Sin 2009, 30:1454-1461.

96. D'Mello NP, Childress AM, Franklin DS, Kale SP, Pinswasdi C, Jazwinski SM: Cloning and characterization of LAG1, a longevity-assurance gene in yeast. J Biol Chem 1994, 269:15451-15459.

97. Jiang JC, Kirchman PA, Allen M, Jazwinski SM: Suppressor analysis points to the subtle role of the LAG1 ceramide synthase gene in determining yeast longevity. Exp Gerontol 2004, 39:999-1009.

98. van Ham TJ, Thijssen KL, Breitling R, Hofstra RM, Plasterk RH, Nollen EA: C. elegans model identifies genetic modifiers of alpha-synuclein inclusion formation during aging. PLoS Genet 2008, 4:e1000027.

99. Tedesco P, Jiang J, Wang J, Jazwinski SM, Johnson TE: Genetic analysis of hyl-1, the C. elegans homolog of LAG1/LASS1. Age (Dordr) 2008, 30:43-52

100. Menuz V, Howell KS, Gentina S, Epstein S, Riezman I, Fornallaz-Mulhauser M, Hengartner MO, Gomez M, Riezman H, Martinou JC: Protection of C. elegans from anoxia by HYL-2 ceramide synthase. Science 2009, 324:381-384

101. Brenner S: The Genetics of Caenorhabditis elegans. Genetics 1974, 77:71-94.

102. Fury W, Batliwalla F, Gregersen PK, Li W: Overlapping probabilities of top ranking gene lists, hypergeometric distribution, and stringency of gene selection criterion. Conf Proc IEEE Eng Med Biol Soc 2006, 1:5531-5534.

103. Aamodt EJ, Chung MA, McGhee JD: Spatial control of gut-specific gene expression during Caenorhabditis elegans development. Science 1991, 252:579-582.

104. Masse I, Molin L, Mouchiroud L, Vanhems P, Palladino F, Billaud M, Solari F: A novel role for the SMG-1 kinase in lifespan and oxidative stress resistance in Caenorhabditis elegans. PLoS One 2008, 3:e3354.

105. Kolasinska-Zwierz P, Down T, Latorre I, Liu T, Liu XS, Ahringer J: Differential chromatin marking of introns and expressed exons by H3K36me3. Nat Genet 2009, 41:376-381

106. Folch J, Lees M, Sloane Stanley GH: A simple method for the isolation and purification of total lipides from animal tissues. J Biol Chem 1957, 226:497-509

107. Thomas JH, Birnby DA, Vowels JJ: Evidence for parallel processing of sensory information controlling dauer formation in Caenorhabditis elegans. Genetics 1993, 134:1105-1117.

108. Melendez A, Greenwald I: Caenorhabditis elegans lin-13, a member of the LIN-35 Rb class of genes involved in vulval development, encodes a protein with zinc fingers and an LXCXE motif. Genetics 2000, 155:1127-1137.

109. Meister P, Towbin BD, Pike BL, Ponti A, Gasser SM: The spatial dynamics of tissue-specific promoters during C. elegans development. Genes Dev 2010, 24:766-782

110. DAVID. [http://david.abcc.ncifcrf.gov/]

doi:10.1186/gb-2011-12-12-r123

Cite this article as: Meister et al: Caenorhabditis elegans

Heterochromatin protein 1 (HPL-2) links developmental plasticity,

longevity and lipid metabolism. Genome Biology 2011 12:R123.

\section{Submit your next manuscript to BioMed Central and take full advantage of:}

- Convenient online submission

- Thorough peer review

- No space constraints or color figure charges

- Immediate publication on acceptance

- Inclusion in PubMed, CAS, Scopus and Google Scholar

- Research which is freely available for redistribution 